\title{
Probing the evolution of palladium species in Pd@MOF cata- lysts during the Heck coupling reaction: An operando X-ray ab- sorption spectroscopy study
}

\author{
Ning Yuan, ${ }^{+,+, \$, \$}$ Vlad Pascanu, ${ }^{+,,, \$}$ Zhehao Huang, ${ }^{+, \neq}$Alejandro Valiente, ${ }^{\dagger, \varnothing}$ Niclas Heidenreich, ${ }^{\perp}$ Sebas- \\ tian Leubner, ${ }^{\perp}$ A. Ken Inge,,,+ Jakob Gaar, ${ }^{,}$Norbert Stock, ${ }^{\perp}$ Ingmar Persson,,${ }^{* *}$ Belén Martín-Matute,,,,$+ * *$ \\ Xiaodong Zou',+** \\ † Berzelii Center EXSELENT on Porous Materials, Stockholm University, SE-106 91 Stockholm, Sweden \\ $\ddagger$ Department of Materials and Environmental Chemistry, Stockholm University, SE-106 91 Stockholm, Sweden \\ $\S$ Department of Molecular Sciences, Swedish University of Agricultural Sciences, P.O. Box 7015, SE-750 07 Uppsala, Sweden \\ ${ }^{x}$ Department of Organic Chemistry, Stockholm University, SE-106 91 Stockholm, Sweden \\ ${ }^{\perp}$ Institut für Anorganische Chemie, Christian-Albrechts-Universität zu Kiel, DE-24118 Kiel, Germany
}

\begin{abstract}
The mechanism of the Heck C-C coupling reaction catalyzed by Pd@MOFs has been investigated using operando Xray absorption spectroscopy (XAS) and powder X-ray diffraction (PXRD) combined with transmission electron microscopy (TEM) analysis and nuclear magnetic resonance $\left({ }^{1} \mathrm{H}\right.$ NMR) kinetic studies. A custom-made reaction cell was used allowing operando PXRD and XAS data collection using high-energy synchrotron radiation. By analyzing the XAS data in combination with ex situ studies, the evolution of the palladium species is followed from the as-synthesized to its deactivated form. An adaptive mechanism is proposed. Mononuclear Pd complexes are found to be the dominant active species at the beginning of the reaction, which then gradually transform into Pd nanoclusters with 13-20 Pd atoms on average in later catalytic turnovers. Consumption of available reagent and substrate leads to coordination of $\mathrm{Cl}^{-}$ions to their surfaces, which causes the poisoning of the active sites. By understanding the deactivation process, it was possible to tune the reaction conditions and prolong the lifetime of the catalyst.
\end{abstract}

\section{INTRODUCTION}

Sustainable catalysis by transition metals ${ }^{1}$ is essential for further advances in the large-scale production of specialty chemicals for pharmaceuticals, advanced materials or agrochemicals. In this context, $\mathrm{C}-\mathrm{C}$ coupling reactions remain indispensable for creating the backbone of organic molecules. To minimize, recycle or replace the heavy metals involved in these processes, for economic and environmental reasons, a thorough understanding of reaction mechanisms is required. The Heck coupling is one such process of utmost importance, forging new $\mathrm{C}$ $\mathrm{C}$ bonds between aryl halides and olefins, in the presence of a metal catalyst, via a two-electron redox cycle. ${ }^{2}$

Detailed investigations into the catalyst activation, nature of active species, factors that govern reactivity and possible deactivation pathways are more difficult to perform in the case of emerging heterogeneous systems such as metal-organic framework (MOF)-supported catalysts, ${ }^{3}$ for which solution-specific characterization methods are not suitable. Heterogeneous mechanisms are notoriously difficult to monitor ${ }^{4,5}$ and adapted operando methods are highly demanding to achieve a deeper understanding. ${ }^{6}$

$\mathrm{X}$-ray absorption spectroscopy (XAS) is a powerful elementspecific technique for investigating the oxidation state and coordination environment of particular atoms in a material, regardless of the aggregation state of the sample (solid, liquid or gas). The concentration of the investigated element can be as low as a few $\mathrm{mM}$. These properties make XAS an ideal method to obtain detailed information about catalytically active centers supported in solid matrices such as MOFs. Moreover, operando XAS methods provide great opportunities to monitor in real time the structural changes of the catalytic center while avoiding interference from the solid support. ${ }^{7}$

Constant improvements in the time resolution of XAS methods led to various reactors being designed and adapted to various reaction conditions. In situ/operando XAS measurements became possible in both gas-solid ${ }^{8}$ and liquid-solid ${ }^{9}$ reaction systems. In the latter case, $\mathrm{Pd}$ nanoparticles supported on active carbon, $\mathrm{Al}_{2} \mathrm{O}_{3}$ or polymers were studied by operando XAS for oxidation ${ }^{10}$ and $\mathrm{C}-\mathrm{C}$ coupling ${ }^{11}$ reactions, revealing mechanistic aspects that were inaccessible with other techniques. Surprisingly, catalytic reactions starting from atomic Pd pre-catalysts are less explored, although they could shed light in the debate over the heterogeneity of Pd-catalyzed processes. ${ }^{12}$

Meanwhile, MOFs ${ }^{13}$ evolved to become the most prolific supports in heterogeneous catalysis today, owing to their recordbreaking porosity and their unprecedented degree of tunability, ${ }^{14}$ which allow more complex catalysts to be embedded in a controlled manner. ${ }^{15}$ Our groups have previously developed MOF-supported Pd catalysts that exhibited excellent reactivity and recyclability for $\mathrm{C}-\mathrm{C}$ cross-coupling reactions, ${ }^{16}$ and for the functionalization of aromatic $\mathrm{C}-\mathrm{H}$ bonds, ${ }^{17}$ which are essential tools for creating new organic molecules. However, preliminary ex situ investigations revealed that despite the apparent recycla- 
bility, the catalyst compositions showed obvious differences before and after the reaction. ${ }^{18}$ In addition, the same MOFsupported catalysts suffered from an unexplainable rapid deactivation in other reactions (e.g. the Heck coupling). These peculiar observations highlighted the necessity to identify better techniques for studying the behavior of MOF-supported catalysts.

A custom reactor was earlier developed by us ${ }^{19}$ for the simultaneous acquisition of operando XAS and powder X-ray diffraction (PXRD) data. This set-up enables the correlation of information about the active catalytic species with the changes in the structural stability of the crystalline solid support. The reactor was designed for operation at synchrotron beamlines. It includes an in-built miniaturized stirring plate and parameters like temperature, pressure as well as the addition of reagents can be controlled remotely. Duplicate experiments under identical conditions were followed by ex situ NMR spectroscopy, transmission electron microscopy (TEM), scanning transmission electron microscopy (STEM), and energy dispersive spectroscopy (EDS). Combining the information extracted from these methods we have unambiguously probed the entire "lifetime" evolution of the Pd species in Pd(II)@MOF pre-catalysts during the Heck coupling reaction. This "lifetime" includes activation of the pre-catalyst, catalysis driven by different types of active species and deactivation of the catalysts. This information further enabled us to manipulate and prolong the activity of our catalyst.

The method described herein is widely applicable to the study of complex catalytic systems promoted by the majority of supported transition metal complexes, where traditional spectroscopic techniques are not sufficient.

\section{EXPERIMENTAL SECTION Materials}

Pd(II)@MIL-101-NH 2, Pd(0)@MIL-101-NH 2, Pd(II)@MIL88B-NH $\mathrm{N}_{2}$ and $\mathrm{Pd}(0) @ \mathrm{MIL}-88 \mathrm{~B}-\mathrm{NH}_{2}$ (Pd@MOF, all with ca. $7-8 \mathrm{wt} \%$ Pd loading) were synthesized according to procedures previously reported. ${ }^{16 a, 20}$ Details of synthesis and characterization are given in Section S1 of the Supporting Information (SI). All reagents and solvents were used as obtained from commercial suppliers without further purification.

\section{Reactor for operando experiments}

Reactions were carried out in a custom-built reactor (Figure 1) developed at the Christian-Albrechts University (Kiel, Germany) in cooperation with the beamline staff at the P08 beamline, PETRA III, DESY (Hamburg, Germany). ${ }^{19}$ The reactor allows the analysis of chemical reactions and crystallographic transformations under solvothermal conditions using synchrotron-based characterization techniques. It consists of an aluminum casing that holds Duran ${ }^{\odot}$ glass vials with a maximum volume of $6 \mathrm{~mL}$. The inner diameter of the vials used was $10 \mathrm{~mm}$ and the thickness of the glass wall was $1.0 \mathrm{~mm}$. The whole reactor was aligned on the beamline in transmission geometry. The aluminum casing was surrounded by a heating mantle made of copper wires. Typically, the reaction mixture was brought to target temperature in less than $1 \mathrm{~min}$. The actual temperature of the reaction mixture was constantly monitored using a PTFEcoated thermocouple and kept close to the target temperature through a combination of resistive heating and direct cooling of the heating mantle with compressed air. To initiate very fast reactions or alter chemical parameters during the reaction, the injection of reagents was triggered remotely via two tubes embedded into the reactor's cap. The tubes were connected to a neMESYS syringe pump fitted with $5 \mathrm{~mL}$ glass syringes. A magnetic stirrer was placed under the base of the aluminum casing to ensure homogeneous distribution of particles in the pathway of the X-ray beam.

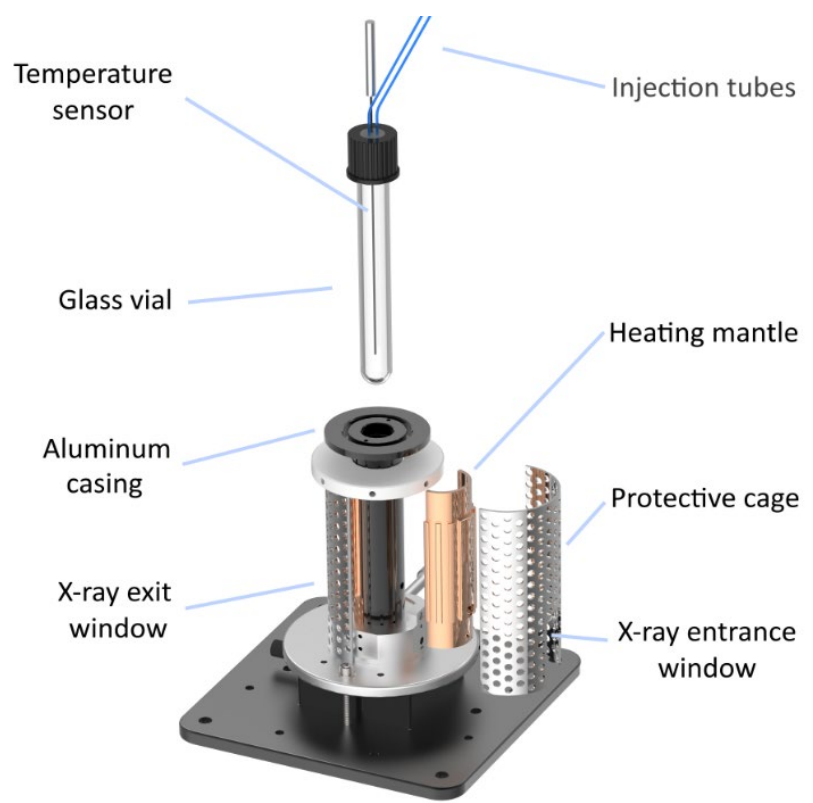

Figure 1. Custom-made reactor for combined operando XAS and PXRD measurements.

\section{Operando XAS and PXRD experiments}

Operando XAS and PXRD data were collected on the beamline BM01B at the ESRF, Grenoble, France. Detailed descriptions of data collection and analysis are given in Section S2. PXRD data were collected on a Dexela 2D detector using X-rays with an energy of $24.55 \mathrm{keV}(\lambda=0.505 \AA) .{ }^{21}$ XAS measurements were performed at the Pd K-edge $(24.35 \mathrm{keV})$ in transmission mode with an energy range from 24.00 to $25.25 \mathrm{keV}$. During the catalytic reactions XAS and PXRD data were collected in bundles of 5 scans each, alternating between the two modes of the beamline. The acquisition of five XAS spectra required ca. $17 \mathrm{~min}$ (3.4 min/scan). The time necessary to switch from XAS to PXRD, collect five diffraction patterns and switch back to XAS was $c a .2 .4 \mathrm{~min}$. This sequence was repeated for the entire duration of the experiment, as described in Figure 2.

For PXRD data, minimal changes were observed between the five consecutive frames. Therefore, intensities from the five frames were summed up in order to improve the intensity statistics. For XAS data, all scans were treated individually as the sample composition changed with time. The data treatment, including pre-edge subtraction, spline removal, normalization and Fourier transformation, was performed with the EXAFSPAK package. ${ }^{22}$ The experimental $k^{3}$-weighted EXAFS oscillations were analyzed by non-linear least-squares fits of the data to the EXAFS equation, refining the model parameters, number of backscattering atoms $(N)$, mean interatomic distances $(R)$, Debye-Waller factor coefficients $\left(\sigma^{2}\right)$, and threshold energy $\left(E_{o}\right)$. The spectrum of a palladium metal foil was recorded simultaneously in transmission mode as reference with the first inflection point of the absorption edge defined as $24.350 \mathrm{keV} .{ }^{23}$ The theoretical phases and amplitudes used in the refinements were 
calculated using the FEFF7 program. ${ }^{24}$ The standard deviations reported for the refined parameters were obtained from $k^{3}$ weighted least-squares refinements of the EXAFS function $\chi(k)$, and without including systematic errors. These statistical error values allow reasonable comparisons, e.g. of the significance of comparing relative shifts in the distances. However, the variations in the refined parameters, including the shift in the $E_{\mathrm{o}}$ value (with $k=0$ ), using different models and data ranges, indicate that the accuracy of the distances given for an individual complex is between \pm 0.005 and $\pm 0.02 \AA$ for welldefined interactions. The "standard deviations" have been increased accordingly to include estimated additional systematic errors.

\section{NMR and TEM experiments}

The experiments at the beamline were repeated in the laboratory under identical conditions in order to acquire NMR and TEM data and correlate it with that obtained by XAS. Small aliquots $(<50 \mu \mathrm{L})$ were taken from the hot reaction mixture at regular intervals, extracted with cold $\mathrm{CDCl}_{3}$ and analyzed by ${ }^{1} \mathrm{H} \mathrm{NMR}$ spectroscopy to measure conversion. The ${ }^{1} \mathrm{H}$ NMR spectra were recorded at $400 \mathrm{MHz}$ on a Bruker Advance spectrometer. Alternatively, a droplet of the aliquot was transferred to a $\mathrm{Cu}$ grid without further treatment. The grid was immediately placed into the vacuum chamber of the microscope for TEM and EDS analysis. TEM observations and EDS mapping were performed on a JEOL JEM-2100F microscope equipped with a Schottky field emission gun, and operated at $200 \mathrm{kV}$. Images were recorded with a Gatan Ultrascan 1000 CCD camera.

\section{Catalytic reactions under standard conditions}

Aryl iodide ( $0.1 \mathrm{mmol})$, olefin (1.3 equiv.), sodium acetate (2 equiv.), and Pd@MOF (0.003 mmol)were stirred in a mixture of deionized water $(0.5 \mathrm{~mL})$ and dimethoxyethane (DME, 1.5 $\mathrm{mL}$ ) in a vial sealed with a septum-fitted cap. The reactions were performed in air. Minimum reactivity was observed at 60 ${ }^{\circ} \mathrm{C}$ and optimal reactivity was observed at $90{ }^{\circ} \mathrm{C}$. Under these conditions, the catalyst was completely deactivated after one run and could not be recycled. Details about the optimization of reaction parameters and the substrate scope are given in Sections S3 and S4. $p$-Iodobenzonitrile and tert-butyl acrylate were chosen as model substrates for the operando experiments (Scheme 1).

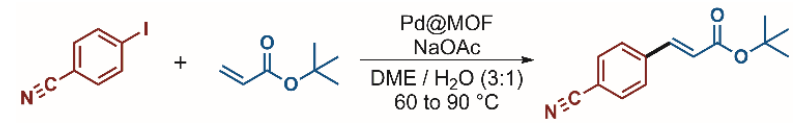

Scheme 1. Model Heck coupling for operando experiments.

\section{Catalytic reactions for operando experiments}

To achieve XAS data of sufficient quality and a rapid completion of the organic reaction, the total concentration of reagents was doubled and the catalyst loading was further increased to ca. $18 \mathrm{~mol} \%$. $p$-Iodobenzonitrile $(0.4 \mathrm{mmol})$, tert-butyl acrylate (1.5 equiv.), NaOAc ( 2 equiv.), and $\mathrm{Pd@MOF} \mathrm{catalyst} \mathrm{(0.075}$ mmol) were mixed in $\mathrm{H}_{2} \mathrm{O}(1 \mathrm{~mL})$ and DME $(3 \mathrm{~mL})$ in $6 \mathrm{~mL}$ vials. Full conversion was typically achieved within $1 \mathrm{~h}$. At higher overall concentrations, an increased viscosity of the reaction medium impeded stirring. Control experiments confirmed that besides an increased reaction rate, no further differences were observed compared to those under standard conditions. Therefore, the conclusions derived from operando studies can be considered relevant for general catalytic experiments.

The following sequence of operations was used as illustrated in Figure 2: 1. $(\mathrm{t}<0 \mathrm{~min}): p$-Iodobenzonitrile $(0.4 \mathrm{mmol}, 91$ $\mathrm{mg}$ ), sodium acetate (2 equiv., $66 \mathrm{mg}$ ) and $\mathrm{Pd} @$ MOF catalyst $(0.075 \mathrm{mmol}, \mathrm{ca} .100 \mathrm{mg}$ for $8 \mathrm{wt} \% \mathrm{Pd}$ loading in MOF) together with $\mathrm{H}_{2} \mathrm{O}(1 \mathrm{~mL})$ and DME $(2 \mathrm{~mL})$ were added to the reaction cell. XAS and PXRD data acquisition was already initiated while the mixture was allowed to stir to homogenize for 10-20 min. 2. ( $\mathrm{t}=0 \mathrm{~min})$ : tert-butyl acrylate (1.5 equiv.) was injected with the remaining solvent (DME, $1 \mathrm{~mL}$ ) and $1 \mathrm{~mL}$ headspace gas was simultaneously extracted to avoid overpressure. 3. $(\mathrm{t}=0-10 \mathrm{~min})$ : the temperature was increased to $60{ }^{\circ} \mathrm{C}$ in less than $1 \mathrm{~min}$ and held constant for $10 \mathrm{~min}$. 4. $(\mathrm{t}=10-30$ $\min )$ : the temperature was further increased by $10^{\circ} \mathrm{C}$ every 10 $\min$ up to $90{ }^{\circ} \mathrm{C}$. 5 . $(\mathrm{t}=30-90 \mathrm{~min})$ : the temperature was maintained constant at $90^{\circ} \mathrm{C}$ for $60 \mathrm{~min}$ to achieve completion of the organic reaction. $6 .(\mathrm{t}>90 \mathrm{~min})$ : the mixture was cooled down gradually to room temperature (RT) during which the XAS and PXRD data acquisition was continued.

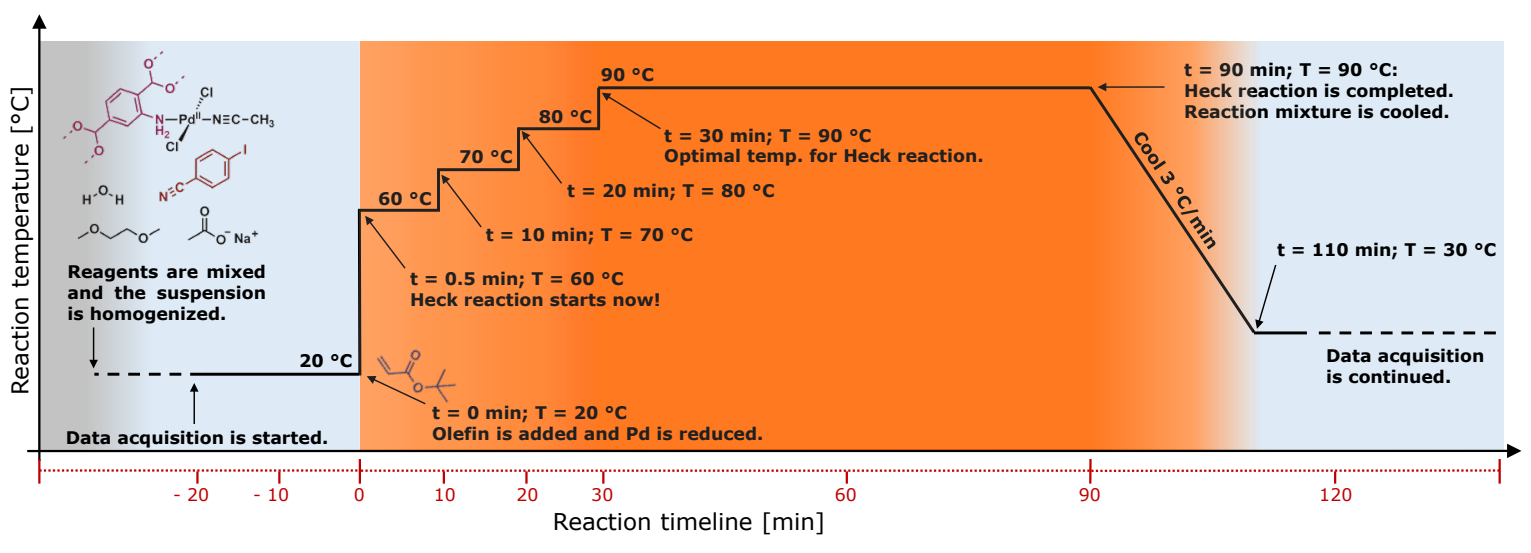

Figure 2. Timeline of the operando XAS and PXRD experiments.

Results and discussion

\section{Catalytic activity (NMR Spectroscopy)}

Kinetic profiles of the Heck reaction using Pd(II)@MIL$101-\mathrm{NH}_{2}$ as pre-catalyst are presented in Figure 3a, where both conversion and temperature are plotted as a function of time. Intriguingly, after an initial short period of rapid conversion at $60^{\circ} \mathrm{C}$, a plateau was reached at $c a .70-80^{\circ} \mathrm{C}$ 
(20-30 min after olefin addition) with a clearly diminished activity (Figure 3a, solid blue line). Upon further heating, the rate increased again and the reaction reached completion in $c a$. $60-70 \mathrm{~min}$. This unusual behavior is indicative of different mechanisms being dominant under different reaction conditions. At the attempt to isolate a single operating mode, we performed additional experiments maintaining the temperature constant at $60^{\circ} \mathrm{C}$. To our surprise, the reaction stopped after only one turnover (Figure 3a, dashed blue line).

We hypothesized that during one of the catalytic steps, after oxidative addition in the first catalytic turnover, $\mathrm{Pd}$ lost its coordination to the MOF linker, due to the poorer coordinating ability of anilines in the MOF compared to ancillary ligands such as phosphines. ${ }^{25}$ This also agrees with our result from XAS showing that the $\mathrm{Pd}-\mathrm{N}$ mean distance decreased from 2.114(8) $\AA$ ( $\mathrm{Pd}$ coordinated to $\mathrm{Ar}-\mathrm{NH}_{2}$ in the MOF) to $1.993(9) \AA$ ( $\mathrm{Pd}$ coordinated to $\mathrm{R}-\mathrm{CN}$ and/or C ligands) at $47 \mathrm{~min}$ (vide infra, Table 1$).{ }^{26}$ Without the nitrogen donor, $\operatorname{Pd}(0)$ species did not have the necessary electron density to perform a second oxidative addition. Furthermore, these $\operatorname{Pd}(0)$ species became mobile and could agglomerate into clusters and further into nanoparticles. Therefore, the plateau observed during the stepwise heating process ( $c$ a $20-30 \mathrm{~min}$, Figure 3a, solid blue line) is likely due to the decreased amount of mononuclear Pd complexes coordinated to the MOF linker while the mobile Pd species are unreactive at low temperature (below $90^{\circ} \mathrm{C}$ ). We anticipated that in order to catalyze the reaction at $60{ }^{\circ} \mathrm{C}, \mathrm{Pd}$ might need to coordinate to a more electron rich ligand (such as $\mathrm{Ar}-\mathrm{NH}_{2}$ ). This was confirmed by adding aniline in stoichiometric amounts to $\mathrm{Pd}$ into the reaction mixture. Aniline represents a small homogeneous model for the MOF linker that can simulate the same coordination mode. Under these conditions, oxidative addition is faster than aggregation, and full conversion was achieved at $60{ }^{\circ} \mathrm{C}$ (Figure $3 \mathrm{a}$, dotted blue line). The shape of the reaction profile suggests a completely homogeneous reaction.

To establish the generality of this behavior, we also tested Pd(II)@MIL-88B-NH 2 , and found that it operates through a related mechanism, with subtle but important differences (Figure 3b, Figure S1, Section S5). When the catalyst was tested at $60{ }^{\circ} \mathrm{C}$, the first turnover occurred at a high rate, as in the case of $\mathrm{Pd}(\mathrm{II}) @ \mathrm{MIL}-101-\mathrm{NH}_{2}$. Afterwards the reaction continued, although at a slower rate, instead of being completely suppressed as for Pd(II)@MIL-101-NH (dashed blue line). When using the stepwise temperature ramp to $90{ }^{\circ} \mathrm{C}$, a similar behavior as for Pd(II)@MIL-101$\mathrm{NH}_{2}$ was observed (solid green line), but the reactivity plateau was less pronounced. We have previously shown that $\mathrm{Pd}(\mathrm{II})$ in MIL-88B- $\mathrm{NH}_{2}$ is coordinated by two amino ligands in a chelating fashion, not only one as in the case of MIL-101-NH $\mathrm{NH}_{2}$ In this way, there is a higher probability that $\mathrm{Pd}$ remains partly coordinated to amino donors in the $\mathrm{MOF}$, even after the first turnover and does not agglomerate as fast as in MIL-101-NH $\mathrm{NH}_{2}$. Thus, although the activity was diminished, this effect was not as drastic as for Pd(II)@MIL-101-NH2. Furthermore, a sustained activity due to coordination to the second MOF linker is also in agreement with literature reports showing that bipyridinetype and other chelating ligands could catalyze the Heck coupling reaction more efficiently. ${ }^{27}$ It is worth mentioning that the kinetic profiles for $\mathrm{Pd}(\mathrm{II}) @ \mathrm{MIL}-101-\mathrm{NH}_{2}$ and Pd(II)@MIL-88- $\mathrm{NH}_{2}$ at the early stage (up to $15 \mathrm{~min}$ ) of the reaction have almost perfect overlap (Figure S2, Section S5). This indicates that the reaction mechanism was the same for both materials at this early stage, and the first catalytic turnover occurred inside the pores.
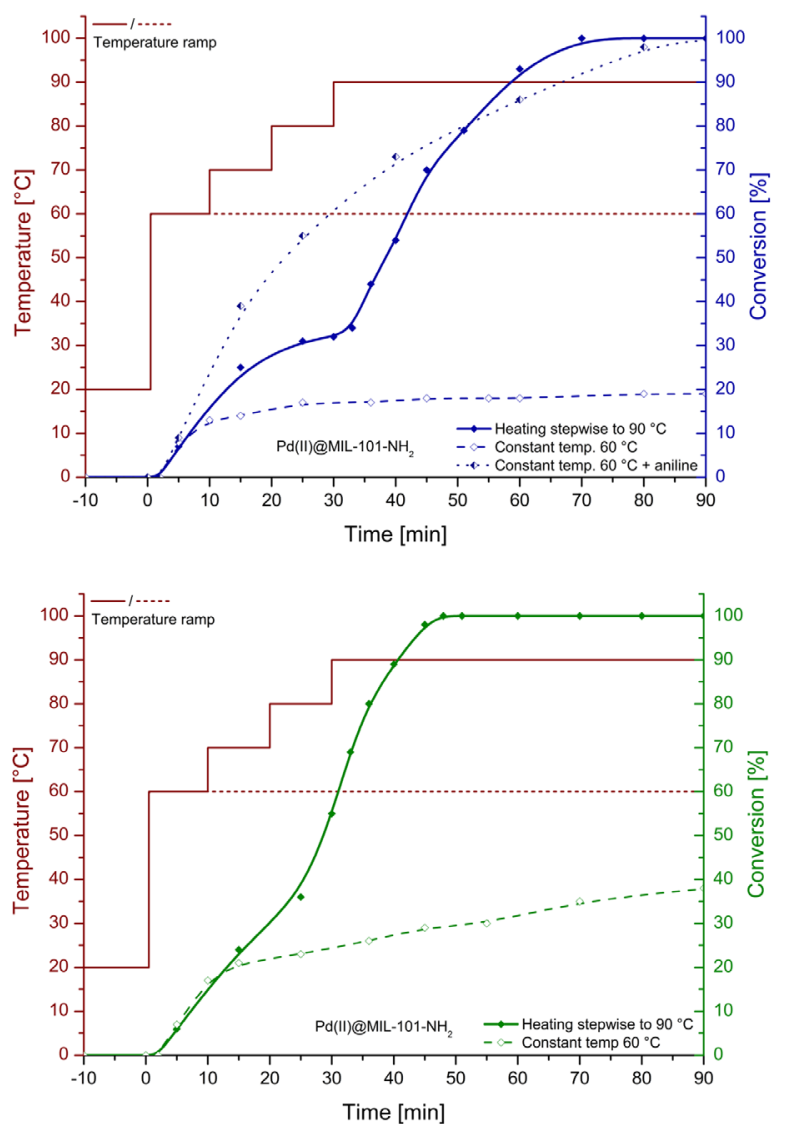

Figure 3. Reaction profile for the Heck coupling catalyzed by Pd(II)@MIL-101-NH2 (a) and Pd(II)@MIL-88B-NH2 (b).

Importantly, when the reaction mixture was heated to 90 ${ }^{\circ} \mathrm{C}$, the reactivity was restored for both catalysts (Figures 3a-3b). This indicates that as-synthesized Pd centers may have changed their coordination environment to form mobile mononuclear Pd complexes and Pd clusters or nanoparticles under the reaction conditions, which altered the reactivity of the catalysts at $90^{\circ} \mathrm{C}$. We anticipate that such drastic changes in the Pd coordination environment should be reflected in the XAS spectra. Indeed, the operando XAS monitoring of the Heck reaction revealed previously unseen details, which support a dynamic, adaptive behavior of $\mathrm{Pd}$ centers upon exposure to physical and chemical stimuli in the reaction mixture. The XAS data is presented in the following section.

\section{Nature of the active species and catalyst de- activation (X-ray absorption spectroscopy)}


X-ray absorption spectroscopy (XAS) revealed that clear changes at the Pd centers occurred as soon as the catalyst was added to the reaction mixture. Both XANES and Fourier transformed (FT) EXAFS of as-synthesized $\mathrm{Pd}(\mathrm{II}) @ \mathrm{MIL}-101-\mathrm{NH}_{2}$, with the formula $[\mathrm{Pd}(\mathrm{Ar}-$ $\left.\left.\mathrm{NH}_{2}\right)\left(\mathrm{CH}_{3} \mathrm{CN}\right) \mathrm{Cl}_{2}\right]$ are markedly different from those recorded in the first operando XAS scan (Figures 4 and 6, Figures S3a-b, Section S6). Even though the Heck reaction had not yet started, anionic $\mathrm{Cl}^{-}$ligands were already replaced by neutral $\mathrm{N}$-ligands, presumably $p$-iodobenzonitrile, which form more stable complexes by several orders of magnitude with $\mathrm{Pd}(\mathrm{II})$ in aqueous media (details can be found in Section S2). ${ }^{28}$

We found that the $\mathrm{Pd}(\mathrm{II})$ in the resulting cationic complex was rapidly reduced upon olefin addition, in a Wacker-type process. ${ }^{29}$ This was proved by carrying out the oxidation of the olefin using Pd(II)@MIL-101-- $\mathrm{NH}_{2}$ (30 mol\% Pd) under the same XAS reaction conditions. Despite the low stability of the resulting $\alpha$-formylacetate derivative in basic media and high temperature, we were able to observe characteristic aldehyde signals (9.9-9.6 ppm) in the ${ }^{1} \mathrm{H}$ NMR spectrum (Figure S4, Section S7). This process required both olefin and water (Figure S5, Section S7). In the absence of $\mathrm{H}_{2} \mathrm{O}, \mathrm{Pd}$ remained in oxidation state $+\mathrm{II}$, even upon heating to $60{ }^{\circ} \mathrm{C}$, and was homogeneously distributed in the MOF crystals as indicated from the TEM images (Figure S5a, Section S7). The in situ generated atomic $\operatorname{Pd}(0)$ triggers the Heck coupling, being re-oxidized in the initial oxidative addition step of the catalytic cycle (vide infra, Figure 8).
The XANES features of as-synthesized Pd(II)@MIL$101-\mathrm{NH}_{2}$ and their evolution as a function of time under Heck conditions is presented in Figure 4. The overview of all XANES spectra recorded during one operando experiment (as described in Figure 2) is shown in Figure 4a. The XANES spectra have the same edge features appeared as one smooth peak at the beginning of the measurement. Then the smooth peak gradually split into two smaller peaks. This overview indicates an initial stable state and thereafter a transformation stage of $\mathrm{Pd}$ species during the measurement.

To follow the changes in detail, representative XANES spectra were selected and compared with as-synthesized Pd(II)@MIL-101-NH $\mathrm{NH}_{2}$ and a metallic Pd foil reference (Figures $4 \mathrm{~b}$ and $4 \mathrm{c}$ ). Figure $4 \mathrm{~b}$ focuses on the initial stages of the reaction. It is noted that the first XANES spectrum recorded under operando measurement condition shows significant changes compared with the XANES spectrum of the as-synthesized Pd(II)@MIL-101- $\mathrm{NH}_{2}$ (Figure 4b, green line). This reveals the changes of the coordination environment of $\mathrm{Pd}$ atoms when the as-synthesized catalyst was added into the reaction mixture. From the start of the operando data acquisition until the reaction temperature reached $80{ }^{\circ} \mathrm{C}$, the XANES spectra overlap and show almost identical edge positions at $24354 \mathrm{eV}$ and similar profiles after the edge. This indicates that no major changes in the coordination environment of Pd occurred from the start of the operando measurement at RT to $80^{\circ} \mathrm{C}$.
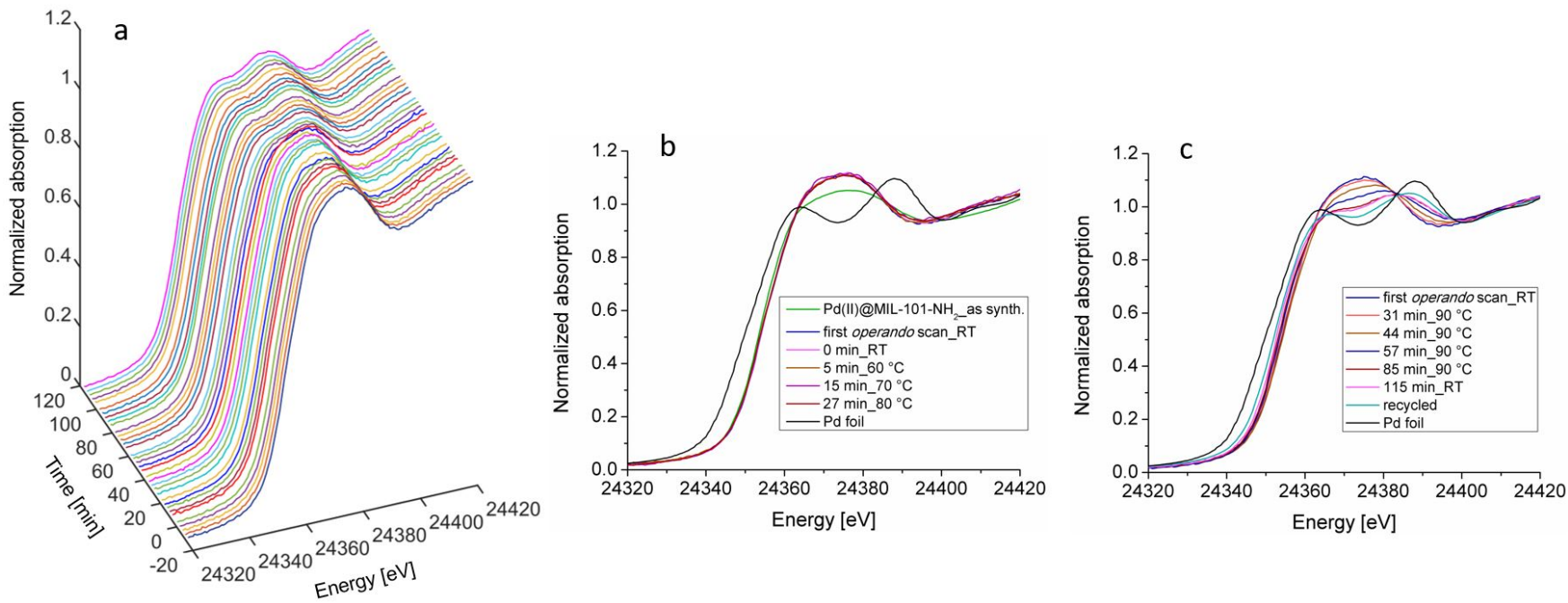

Figure 4. Normalized Pd K-edge XANES spectra of Pd(II)@MIL-101-NH $\mathrm{N}_{2}$ catalyst as a function of measurement time. (a) All XANES spectra displayed in three-dimensions. (b) Selected XANES spectra showing the as-synthesized Pd(II)@MIL-101-NH2, the heating steps and Pd reference. (c) Selected XANES spectra at RT, $90^{\circ} \mathrm{C}$, cooling back to RT, recycled and Pd reference. 


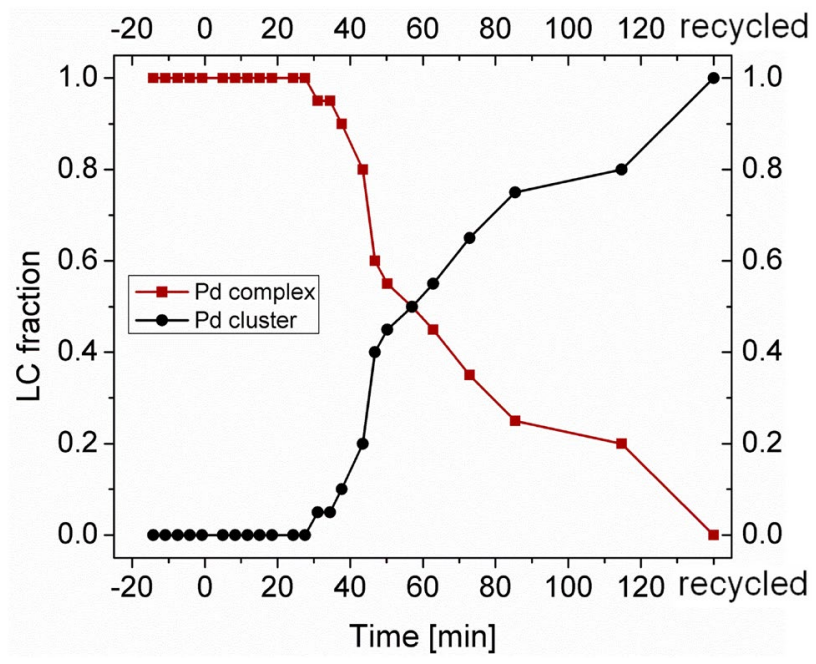

Figure 5. Fractions of mononuclear $\mathrm{Pd}(\mathrm{II})$ complexes and $\mathrm{Pd}(0)$ nanoclusters in the catalyst derived from the linear combination fit of the XANES spectra.

During this period, edge positions are located close to the assynthesized Pd(II)@MIL-101- $\mathrm{NH}_{2}$ and about $4 \mathrm{eV}$ above the Pd foil reference, which has the oxidation state zero and K-edge position at $24350 \mathrm{eV}$. Considering that a one-step change in oxidation number commonly introduces a K-edge shift to a higher energy by 2.0 to $2.5 \mathrm{eV}$. These results confirm that Pd mainly maintained an oxidation state of + II during this reaction period. ${ }^{30}$ These observations are in agreement with the NMR data (vide supra), suggesting that the freshly reduced $\operatorname{Pd}(0)$ was short-lived and reacted immediately upon heating to $60{ }^{\circ} \mathrm{C}$. It is thus reasonable that at sufficiently high concentration of aryl iodide, $\mathrm{Pd}$ is re-oxidized much faster than the time resolution of the present experiments ( $c a .3 .4 \mathrm{~min} / \mathrm{XAS}$ scan). A cationic resting state at $\mathrm{Pd}(\mathrm{II})$ during the catalytic cycle is likely to be the one observed by XAS, thus not showing major differences from the pre-catalyst. Figure $4 \mathrm{c}$ includes selected XANES spectra of Pd(II)@MIL-101- $\mathrm{NH}_{2}$ covering the entire experiment. The spectrum of the recycled catalyst and that of the Pd foil are also included. When the system was heated to $90{ }^{\circ} \mathrm{C}$, changes in the XANES spectra were observed compared to those recorded at temperatures lower than $90^{\circ} \mathrm{C}$. The edge features began to resemble those of the $\mathrm{Pd}$ foil, and the $\mathrm{Pd} \mathrm{K}$-edge position shifted towards a lower energy. These changes became even more pronounced for the recycled catalyst and its edge position further shifted to $24352 \mathrm{eV}$ indicating the average oxidation state of $\mathrm{Pd}$ was close to $+\mathrm{I}$. These observations suggest a gradual increase in the degree of transformation of mononuclear Pd(II) complexes into $\mathrm{Pd}(0)$ nanoclusters and the $\mathrm{Pd}$ atoms in recycled catalyst remained in a partially oxidized form.

The composition of Pd species during this transformation and their corresponding ratios were studied by linear combination fit (LCF) of the XANES spectra. Detailed LCF fit and analysis are described in Figure S6 and Section S8. The fairly good fit results confirm that the catalysis system consisted of mononuclear $\mathrm{Pd}(\mathrm{II})$ complexes and $\mathrm{Pd}(0)$ nanoclusters. The fractions of different $\mathrm{Pd}$ components during the operando experiment are displayed in Figure 5. At the start of the operando measurement, the catalyst consisted of $100 \%$ mononuclear Pd(II) complexes and $0 \%$ nanoclusters. The complexes started transforming into nanoclusters from $31 \mathrm{~min}$ when the temperature reached $90{ }^{\circ} \mathrm{C}$. Generally, the rate of transformation was high in the beginning of the transformation appearing as steep slopes and then decreased. The transformation accomplished in the recycled catalyst where only $\operatorname{Pd}(0)$ nanoclusters were present.

The specific coordination environment of $\mathrm{Pd}$ atoms in the MOF was further investigated by analyzing the corresponding FT EXAFS spectra from the same operando experiment (Figure 6). The FT spectrum of the as-synthesized Pd(II)@MIL-101$\mathrm{NH}_{2}$ is shown in Figure 6 (-22 min) which contains two major peaks corresponding to the $\mathrm{Pd}-\mathrm{N}$ and $\mathrm{Pd}-\mathrm{Cl}$ bonds. Refinement of the data suggests a formula $\left[\mathrm{Pd}\left(\mathrm{ArNH}_{2}\right)\left(\mathrm{CH}_{3} \mathrm{CN}\right) \mathrm{Cl}_{2}\right]$. During the first part of the operando measurement, the temperature of the reaction system was increased from RT to $90{ }^{\circ} \mathrm{C}$ (up to $31 \mathrm{~min}$ ) and the FT spectra are very similar with only one major peak corresponding to $\mathrm{Pd}-\mathrm{N} / \mathrm{C}$ bonds with an average coordination number of 4 . The $\mathrm{Pd}-\mathrm{Cl}$ bonds disappeared immediately when the as-synthesized catalyst was added into the reaction mixture. EXAFS spectra recorded at $24 \mathrm{~min}\left(\right.$ at $80^{\circ} \mathrm{C}$ ) and 34 $38 \mathrm{~min}\left(\right.$ at $\left.90{ }^{\circ} \mathrm{C}\right)$ are excluded because of the untreatable data quality (this phenomenon is discussed in Section S2). Interestingly, after the temperature was stabilized at $90^{\circ} \mathrm{C}$, the EXAFS data quality was quickly recovered. At this stage (from $31 \mathrm{~min}$ ), a peak corresponding to $\mathrm{Pd}-\mathrm{Pd}$ bonds appeared and later became clearly visible with increasing intensity. Importantly, as the $\mathrm{Pd}-\mathrm{Pd}$ peak became more prominent, a $\mathrm{Pd}-\mathrm{Cl}$ peak also emerged, while the $\mathrm{Pd}-\mathrm{N} / \mathrm{C}$ peak decreased in intensity. It should be noted that the shoulder side peak of $\mathrm{Pd}-\mathrm{Pd}$ bond in the Fourier transform is at about the same position of the peak corresponding to $\mathrm{Pd}-\mathrm{Cl}$ bond. A thorough EXAFS data analysis proving the existence of $\mathrm{Pd}-\mathrm{Cl}$ bonds can be found in Figures S7-S10 and Section S9. In addition to the confirmation from EXAFS data, inductively-coupled plasma atomic-emission spectroscopy (ICP-OES) was used to determine the element composition of the recycled catalyst. The results showed that significant amount of chloride $(1.05 \mathrm{wt} \%)$ remained in the recycled catalyst. The molar ratio of $\mathrm{Pd} / \mathrm{Cl}$ derived from ICP-OES results is $c a$. 1.2. This is in good agreement with the result from the EXAFS refinement (Table 1) which implies that each Pd atom was bound to one $\mathrm{Cl}^{-}$ion on average.

These observations from FT spectra are consistent with the information obtained from XANES spectra suggesting the formation of mononuclear Pd(II) complexes from the as-synthesized catalyst followed by the continuous transformation of mononuclear $\mathrm{Pd}(\mathrm{II})$ complexes into $\mathrm{Pd}(0)$ nanoclusters when the reaction system was heated to $90^{\circ} \mathrm{C}$. The existence of $\mathrm{Pd}-\mathrm{Cl}$ also explains the oxidation state of $\mathrm{Pd}$ in the recycled catalyst determined by its K-edge position.

Local structures of the Pd atoms during the operando measurement were determined by fitting of the EXAFS spectra corresponding to the FTs in Figure 6. A maximum of three shells of $\mathrm{Pd}---\mathrm{Pd}$, one shell of $\mathrm{Pd}-\mathrm{N} / \mathrm{C}$ and one shell of $\mathrm{Pd}-\mathrm{Cl}$ distances were introduced to optimize the EXAFS fitting. FT spectra of $\mathrm{Na}_{2} \mathrm{PdCl}_{4}$ and $\mathrm{Pd}$ foil were used as references to confirm the $\mathrm{Pd}-\mathrm{Cl}$ and $\mathrm{Pd}-\mathrm{Pd}$ bonds in our system. The model for fitting $\mathrm{Pd}$---Pd was the crystalline structure of metallic palladium, with face-centered cubic packing. The experimental EXAFS spectra and their best fits are shown in Figures S3, Section S6. The final fitting parameters are given in Table 1 . The average size (i.e. average number of $\mathrm{Pd}$ atoms) of the 


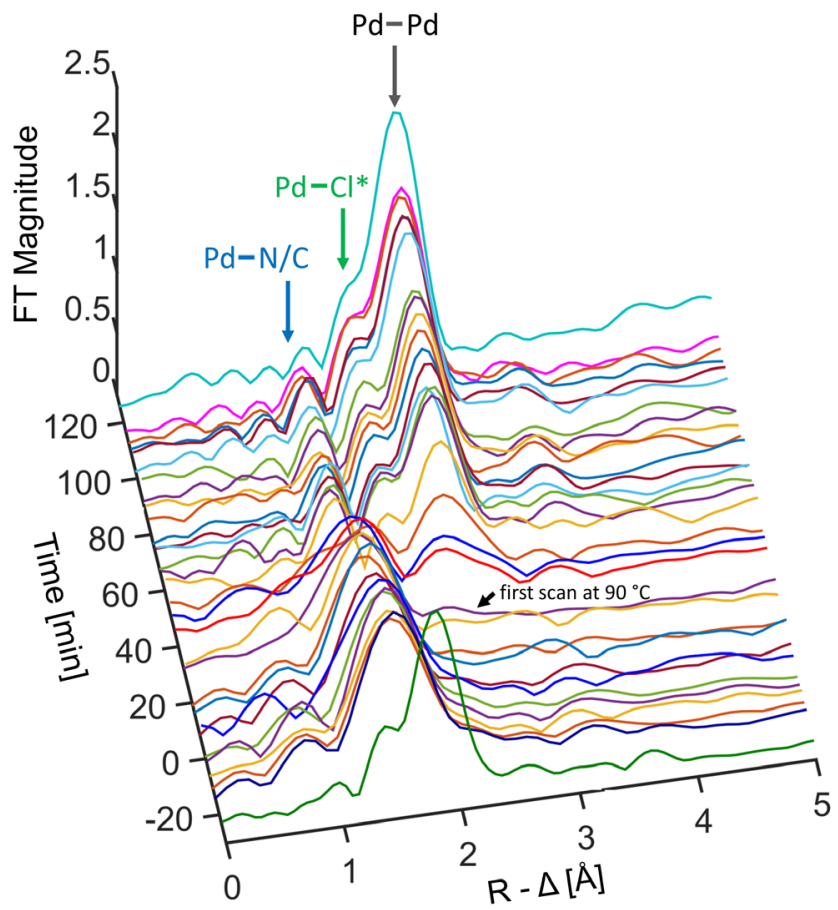

Figure 6. Fourier transformed $k^{3}$-weighted EXAFS data as a function of time showing the coordination environment of $\mathrm{Pd}$ in Pd(II)@MIL-101-NH2. The spectra are not phase corrected. * The peak at ca. $1.9 \AA$ comprises signal of $\mathrm{Pd}-\mathrm{Cl}$ single scattering and the side peak of $\mathrm{Pd}-\mathrm{Pd}$ single scattering.

Pd clusters was estimated from the coordination numbers $(\mathrm{CN})$ of $\mathrm{Pd}-\mathrm{Pd}$ in the first shell refined from the EXAFS data. ${ }^{31} \mathrm{It}$ shall be noticed that the $\mathrm{CN}$ values determined from EXAFS refinements are average values without taking into account of the fraction of each $\mathrm{Pd}$ species. The true $\mathrm{CN}$ values for $\mathrm{Pd}-\mathrm{Pd}$ equal to the $\mathrm{CN}$ values from EXAFS refinement divided by the corresponding fractions of the Pd nanoclusters. It shall be stressed that the Pd nanoclusters transformed from mononuclear Pd complexes are on average smaller than $1 \mathrm{~nm}$ in size and each cluster consists of ca. $13 \mathrm{Pd}$ atoms. They are considerably smaller than the nanoparticles in commercial catalysts, such as $\mathrm{Pd} @ \mathrm{C}_{2}{ }^{11 \mathrm{a}, 32} \mathrm{Pd} @ \mathrm{Al}_{2} \mathrm{O}_{3}{ }^{8 \mathrm{f}, 10 \mathrm{a}, 32 \mathrm{~b}}$ and $\mathrm{Pd} @$ polymers. ${ }^{11 \mathrm{c}}$ Meanwhile, the mean Pd-Pd bond distances in the Pd nanoclusters were also determined from EXAFS refinements (Table 1), and they are between $2.65-2.67 \AA$. Interestingly, these bond distances are significantly shorter than the distances found in $\mathrm{Pd}$ foil $(2.74 \AA)$ and Pd nanoparticles with size of ca. $2 \mathrm{~nm}(\geq 2.71$ $\AA) .{ }^{10,11}$ It is known that Pd atoms on the surface of Pd nanoparticles form shorter $\mathrm{Pd}-\mathrm{Pd}$ bonds compared with $\mathrm{Pd}$ atoms at interior due to lower coordination number of the surface atoms. ${ }^{33}$ The average bond distances of $\mathrm{Pd}-\mathrm{Pd}$ and their corresponding particle sizes had also been investigated by an accurate all-electron density functional approach. ${ }^{34}$ These previous studies strongly support the Pd nanoclusters model we proposed here including the bond distance and average nanocluster size. With an average cluster size of ca. 13 atoms, most of the Pd atoms are on the surface of the nanoclusters. Therefore, such small Pd nanoclusters should still be highly catalytically active, judged by size alone ${ }^{35}$ and by the number of Pd atoms with coordination sites available. However, the rise of the $\mathrm{Pd}-\mathrm{Cl}$ peak in the Fourier transforms offers a first hint into the real motive behind the catalyst deactivation.

The average coordination number of $\mathrm{Pd}-\mathrm{N} / \mathrm{C}$ maintained at 4.0 when there was no transformation of $\mathrm{Pd}(\mathrm{II})$ species. As the mononuclear $\mathrm{Pd}(\mathrm{II})$ started to reconstruct into $\mathrm{Pd}(0)$ nanoclusters, the average $\mathrm{CN}$ of $\mathrm{Pd}-\mathrm{N} / \mathrm{C}$ decreased to $c a$. 3.4 at $44 \mathrm{~min}$ and to $c a .0 .8$ at $115 \mathrm{~min}$ indicating a continuous transformation process. The first $\mathrm{Pd}-\mathrm{Cl}$ bonds were observed after $57 \mathrm{~min}$ with an average $\mathrm{CN}$ of $c a$. 0.4 . The reaction conversion had at this time already reached $c a .95 \%$ (Figure $3 \mathrm{a}$ ). The average $\mathrm{CN}$ then further increased and ended up at $c a$. 1.0. It shall be noted that the bond distances of the reformed $\mathrm{Pd}-\mathrm{Cl}$ bonds were 2.35-2.42 $\AA$, which is significantly longer than those in $\mathrm{Pd}(\mathrm{II})$ complexes. This indicates that the $\mathrm{Pd}$ atoms coordinated to $\mathrm{Cl}^{-}$were surface atoms of the Pd nanoclusters, where each Pd atom bound to several $\mathrm{Pd}$ atoms and the $\mathrm{Pd}-\mathrm{Cl}$ bonds became longer in comparison with $\mathrm{Pd}(\mathrm{II})$ complexes. This also indicates that when $\mathrm{Cl}^{-}$ ions are coordinated to the relatively bulky and less mobile $\mathrm{Pd}$ nanoclusters, they could not easily be replaced by the amino groups of the MOF linkers.

The recycled Pd(II)@MIL-101-- $\mathrm{NH}_{2}$ was measured by ex situ EXAFS (Figure S3f, Section S6). No EXAFS signal from $\mathrm{Pd}-\mathrm{N} / \mathrm{C}$ distances was found from the refinement and average coordination numbers of $\mathrm{Pd}-\mathrm{Pd}$ and $\mathrm{Pd}-\mathrm{Cl}$ bonds were determined to be $c a$. 6.5 and $c a$. 1.0, respectively. The $\mathrm{Pd}-\mathrm{Pd}$ bond distance is longer (ca. 2.69 $\AA$ ) than Pd-Pd bond distances $(2.65$ - $2.67 \AA$ ) during operando measurement (44 - $115 \mathrm{~min})$ indicating larger clusters, but still shorter than the Pd-Pd distance of a $2 \mathrm{~nm} \mathrm{Pd}$ nanoparticle. It is reasonable to propose that at this stage of the process, Pd nanoclusters became the absolute dominating species with an average size of $c a .20$ atoms, ${ }^{34}$ and the surfaces of these Pd nanoclusters were almost covered by $\mathrm{Cl}^{-}$ ions leading to the deactivation of the catalyst.

It shall be noted that the coordination numbers and the estimated sizes of Pd clusters obtained from the EXAFS fitting are an average of various Pd species. In reality, it is likely that both larger Pd nanoparticles with higher coordination numbers and smaller Pd clusters with lower coordination numbers coexist in the sample.

Based on the operando XANES and EXAFS analyses, the evolution of Pd species was followed and the catalytically active species under Heck conditions were identified. The kinetic profile (vide supra) of the identified Pd species are illustrated in Figure 7. The active species were mononuclear Pd(II) complexes coordinating to the linkers of the MOF at the beginning of the reaction below $90^{\circ} \mathrm{C}$. The mononuclear Pd(II) complexes then dissociated from the linkers after one run and their activity was lost when the temperature was lower than $90{ }^{\circ} \mathrm{C}$. As the temperature was raised and maintained at $90{ }^{\circ} \mathrm{C}$, these mobile mononuclear $\mathrm{Pd}(\mathrm{II})$ complexes gradually converted to $\mathrm{Pd}$ nanoclusters of ca. $13 \mathrm{Pd}$ atoms on average. A mixture of the mobile mononuclear Pd(II) complexes and Pd nanoclusters coexisted and became the active species to catalyze the reaction. The activity of the mobile mononuclear Pd complexes at $90{ }^{\circ} \mathrm{C}$ was confirmed by adding a second load of reagents at $70 \mathrm{~min}$, when the system consisted of ca. 40\% mononuclear Pd complexes and $60 \% \mathrm{Pd}$ nanoclusters covered and poisoned by coordinated $\mathrm{Cl}^{-}$ions (Figure 7). A full conversion of the new reagents was achieved in another $70 \mathrm{~min}$ at $90{ }^{\circ} \mathrm{C}$. This experimental result proved that the mobile $\mathrm{Pd}$ mononuclear complexes are catalytically active after the reaction system was heated to $90{ }^{\circ} \mathrm{C}$ during the operando measure- 
Table 1. Refined distances $(\mathrm{d} / \AA ̊)$, and mean number of distances $(\mathrm{N})$ in selected scans using the Pd(II)@MIL-101-NH ${ }_{2}$ catalyst.

\begin{tabular}{|c|c|c|c|c|c|c|c|c|c|c|}
\hline Catalyst & $\begin{array}{c}\text { d(Pd- } \\
\mathbf{N} / \mathbf{C})(\AA)^{a} \\
\end{array}$ & $\mathbf{C N}^{b}$ & $\begin{array}{c}\mathbf{d}(\mathbf{P d}-\mathbf{C l}) \\
(\AA)^{a} \\
\end{array}$ & $\underset{b}{\mathbf{C N}}$ & $\begin{array}{c}\text { d(Pd } \cdots \text { Pd }) \\
1 \text { st shell } \\
\end{array}$ & $\mathrm{CN}^{b, c}$ & $\begin{array}{c}\mathbf{d}(\mathbf{P d} \cdots P \mathbf{P d}) \\
\text { 2nd shell }(\AA)^{a}\end{array}$ & $\underset{b}{\mathbf{C N}}$ & $\begin{array}{c}\mathbf{d}(\mathbf{P d} \cdots \mathbf{P d}) \\
\text { 3rd shell }(\AA)^{a}\end{array}$ & $\mathbf{C N}^{b}$ \\
\hline As synth. & $2.114(8)$ & 2.0 & $2.298(1)$ & 2.0 & - & - & - & - & - & - \\
\hline First scan & $2.083(6)$ & $\overline{4.0}$ & - & $\overline{-}$ & - & - & - & - & - & - \\
\hline $31 \mathrm{~min}$ & $2.056(4)$ & $\underline{3.8}$ & & & $2.710(7)^{\mathrm{d}}$ & $\underline{0.4(8.0)^{\mathrm{d}}}$ & & & & \\
\hline $44 \mathrm{~min}$ & $2.037(6)$ & 3.4 & - & - & $2.674(5)$ & $0.8(4.0)$ & - & - & - & - \\
\hline $47 \mathrm{~min}$ & $1.993(9)$ & 2.9 & - & - & $2.666(7)$ & $1.8(4.5)$ & $3.68(2)$ & 1.0 & - & - \\
\hline $50 \mathrm{~min}$ & $2.026(8)$ & 2.8 & - & - & $2.655(4)$ & $2.7(6.0)$ & $3.82(2)$ & $\underline{1.0}$ & - & - \\
\hline $57 \mathrm{~min}$ & $1.980(6)$ & $\overline{1.3}$ & $2.37(1)$ & $\underline{0.4}$ & 2.654(4) & $\underline{2.8(5.6)}$ & $3.76(2)$ & $\overline{1.0}$ & $4.68(2)$ & $\underline{2.0}$ \\
\hline $63 \mathrm{~min}$ & $1.956(5)$ & $\overline{1.0}$ & $2.35(1)$ & $\overline{0.7}$ & $2.653(4)$ & $3.1(5.6)$ & $3.74(4)$ & $\overline{1.0}$ & $4.73(2)$ & $\overline{2.0}$ \\
\hline $73 \mathrm{~min}$ & $1.979(7)$ & $\overline{0.8}$ & $2.38(2)$ & $\overline{1.0}$ & $2.662(3)$ & $3.2(4.9)$ & $3.76(1)$ & $\overline{1.0}$ & $4.73(1)$ & $\overline{2.0}$ \\
\hline $85 \mathrm{~min}$ & $1.959(7)$ & $\underline{0.9}$ & $2.38(1)$ & 1.0 & $2.662(3)$ & $3.7(4.9)$ & $3.78(2)$ & 1.0 & $4.75(1)$ & 2.0 \\
\hline $115 \min$ & $1.978(7)$ & $\underline{0.8}$ & $2.384(7)$ & 1.0 & $2.662(2)$ & $\underline{4.2(5.3)}$ & $3.76(2)$ & $\underline{2.0}$ & $4.85(1)$ & $\underline{3.0}$ \\
\hline Recycled & & & $2.415(3)$ & $\overline{1.0}$ & $2.689(1)$ & 6.5 & $3.815(6)$ & $\overline{3.0}$ & $4.747(3)$ & $\overline{6.0}$ \\
\hline Pd foil & & & & & $2.741(1)$ & 12.0 & $3.904(8)$ & $\underline{6.0}$ & $4.767(2)$ & $\underline{24.0}$ \\
\hline
\end{tabular}

${ }^{a}$ The standard deviations in parentheses were obtained from $k^{3}$-weighted least square refinements of the EXAFS function $\chi(k)$ and do not include systematic errors of the measurement. ${ }^{b}$ The estimated error of the coordination is $c a .25 \%$ of the given value when refined. Underscored parameters have been optimized and fixed in the refinements. ${ }^{c}$ The $\mathrm{CN}$ values in parentheses are the true coordination numbers of $\mathrm{Pd}-\mathrm{Pd} 1^{\text {st }}$ shell when the fractions of $\mathrm{Pd}$ nanoclusters were taken into account. These values were used to determine the average size of Pd nanoclusters. ${ }^{d}$ The bond distance and $\mathrm{CN}$ value of Pd-Pd $1^{\text {st }}$ shell at $31 \mathrm{~min}$ contain relatively big errors because of the weak EXAFS signal when Pd nanoclusters just started to form.

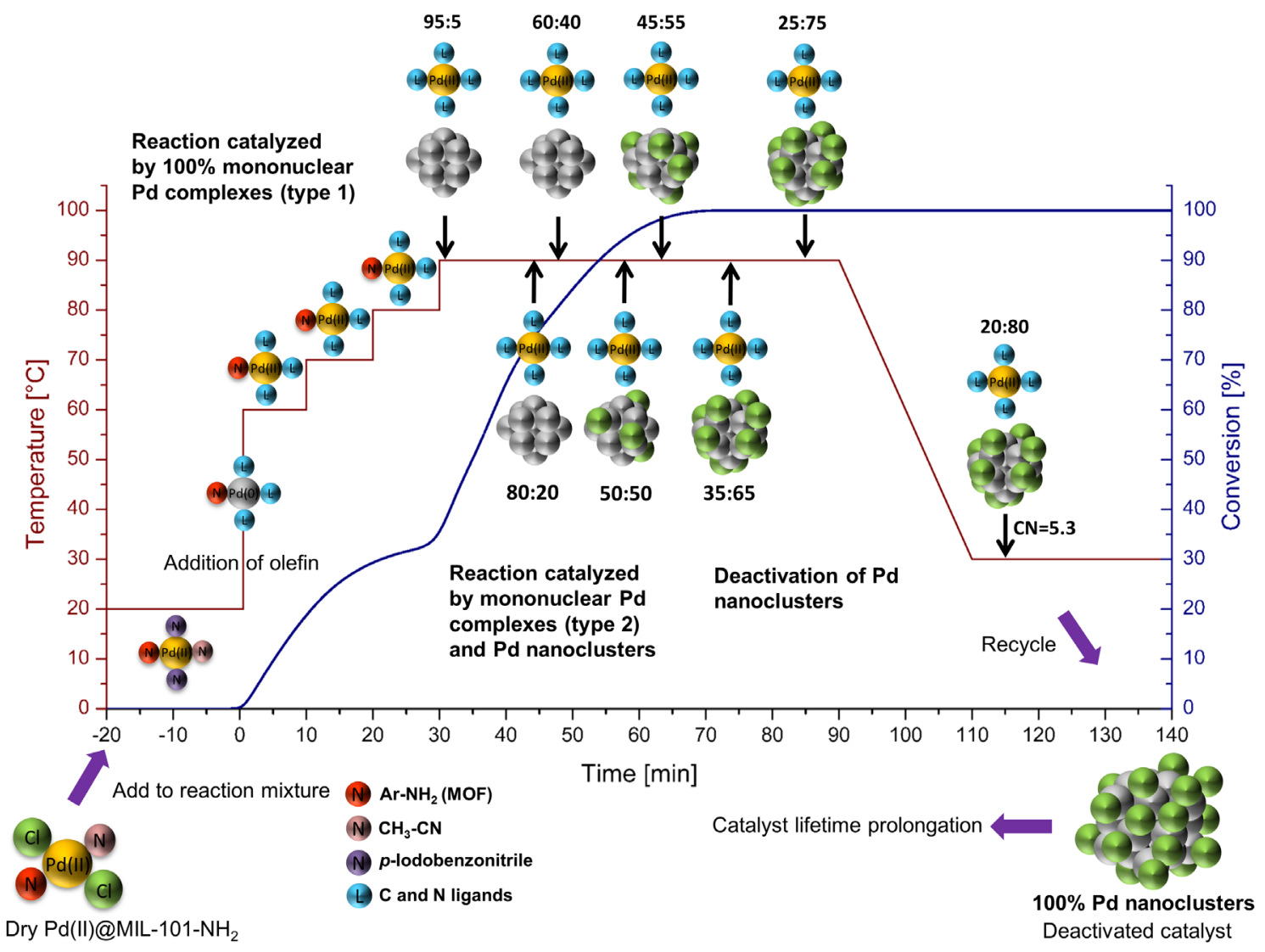

Figure 7. Proposed Pd species at different stages during the Heck coupling reaction using Pd(II)@MIL-101-NH 2 as a catalyst. The red trace shows the temperature and the blue trace shows conversion to the desired product. The value of $\mathrm{CN}$ in the figure refers to the coordination number of $\mathrm{Pd}-\mathrm{Pd}$ in the first shell. 


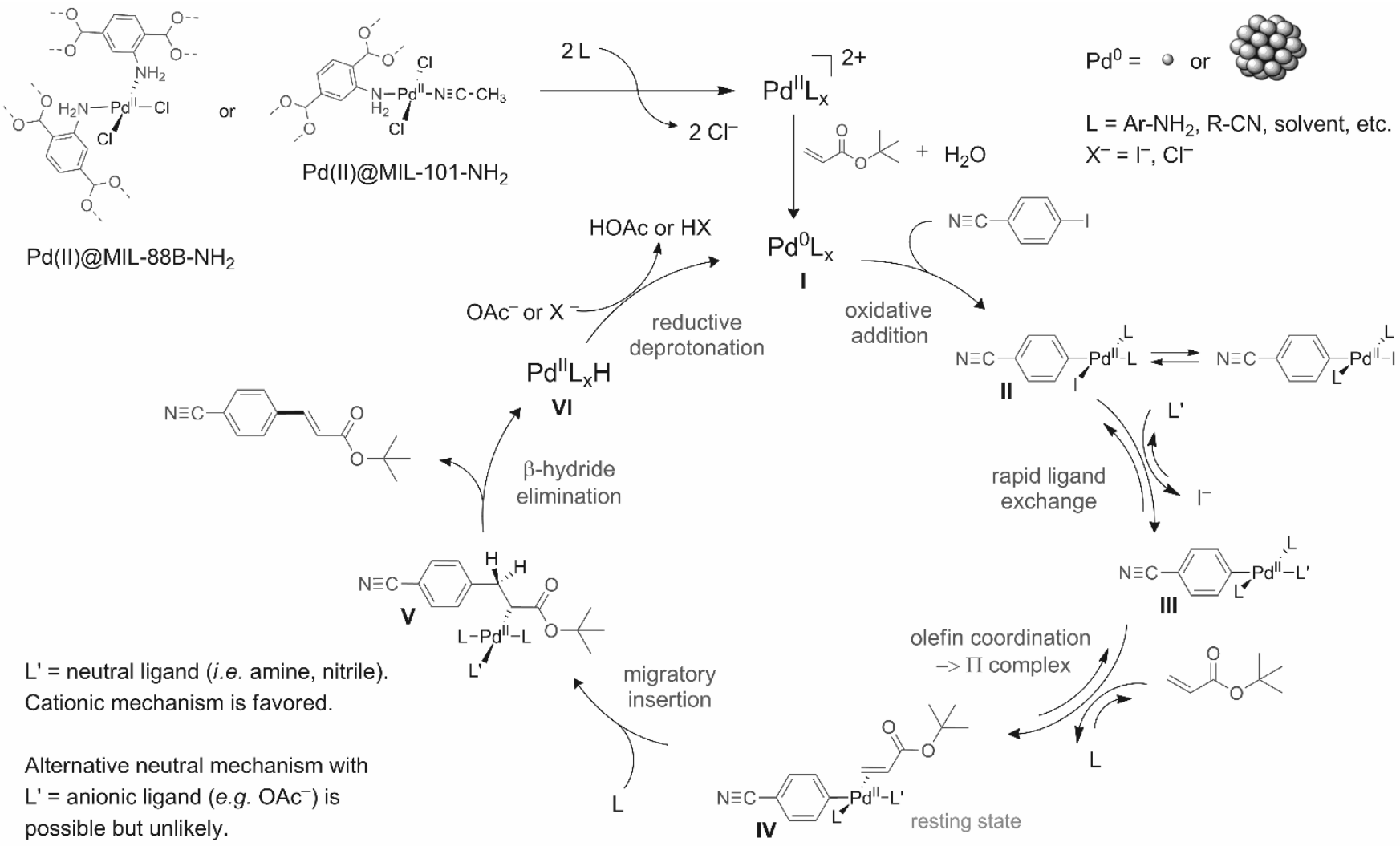

Figure 8. Proposed mechanism for the Heck coupling reaction catalyzed by $\mathrm{Pd}(\mathrm{II}) @ \mathrm{MIL}-101-\mathrm{NH}_{2}$.

ment. At the beginning of this stage, mononuclear Pd complexes appeared also as the major Pd species compared to the Pd nanocluster. The mononuclear Pd complexes have even better activity than the corresponding Pd nanoclusters considering the size and the number of coordination sites available. This continuous conversion of the Pd species also indicated that mononuclear Pd complexes had a relatively high activity because it could compete with the aggregation process under the reducing conditions. After $\mathrm{Cl}^{-}$ions were bound to the surface of the Pd nanoclusters, the remaining mononuclear Pd(II) complexes catalyzed the reaction to its completion. When the substrates were completely consumed, mononuclear Pd complexes could not react and they self-aggregated into Pd nanoclusters, which were quickly poisoned by remaining $\mathrm{Cl}^{-}$ions in the system. A similar evolution of $\mathrm{Pd}$ species was also observed from Pd(II)@MIL-88B-NH ${ }_{2}$ catalyzed reaction. The corresponding XANES and EXAFS spectra can be found in Figure S11, Section $\mathrm{S} 10$

A mechanism derived from the above-described investigations is proposed and shown in Figure 8. The freshly produced $\operatorname{Pd}(0)$ complex $(\mathbf{I})$ represents the active species that initiate the catalytic cycle by oxidative addition in the $\mathrm{C}-\mathrm{I}$ bond, leading to the $\operatorname{Pd}\left(\mathrm{L}_{2}\right)$ ArI intermediate (II). The absence of any Pd-I distances in the EXAFS data is not surprising. The oxidative addition is rapidly followed by a ligand exchange reforming the favored cationic species stabilized by a neutral N-ligand, following a similar preference as observed in the early stages of the experiment. This leads to an intermediate complex (III), to which the olefin coordinates to form a $\pi$-complex (IV). Intermediates III and IV contain solely $\mathrm{Pd}-\mathrm{C} / \mathrm{N}$ bonds, in agreement with the XAS data. Based on this analysis, it is reasonable to conclude that the resting state of Pd species observed by XAS in the early stages of the measurement corresponds to intermediate IV, in which Pd has an oxidation state of + II. This is also in agreement with numerous reports that pointed out the migratory insertion step to be turnover-limiting. In the following step, a $\beta$-hydride elimination yields the final organic product and a palladium hydride species (VI) that upon reductive deprotonation returns to $\mathrm{Pd}(0)$, completing this cycle.

\section{Framework stability and catalyst distribution inside the MOFs (TEM, EDS, PXRD)}

Duplicate experiments were recreated as described in Figure 2 and monitored by TEM and STEM/EDS. The distribution of Pd in MIL-101- $\mathrm{NH}_{2}$ crystals was investigated at various stages during the Heck coupling reaction (Figure 9). To minimize possible Pd aggregation introduced during the TEM sample preparation, a droplet of the hot reaction mixture was directly deposited onto the TEM grid and transferred into the vacuum chamber of the microscope. At the initial stage, no Pd nanoparticles were visible in the TEM images, both inside and outside MIL$101-\mathrm{NH}_{2}$ crystals (Figure $9 \mathrm{a}_{1}$ ). In addition, EDS mapping showed the presence of homogenously distributed Pd throughout the framework (Figure $9 b_{1}$ ). This confirms that the pre-catalyst consisted of Pd(II) complexes, embedded inside the MIL$101-\mathrm{NH}_{2}$. After the Heck reaction was initiated, TEM images recorded at various stages of the reaction $(25 \%, 54 \%$ and $>99 \%$ conversion) showed formation of Pd nanoparticles of 2-15 nm in size on the surfaces of the crystals (Figures $9 a_{2}-9 a_{4}$ ). The presence of the Pd nanoparticles shown in Figure $9 \mathrm{a}_{2}$ (25\% conversion at $70^{\circ} \mathrm{C}$ ) was probably caused by transformation of $\mathrm{Pd}$ complexes into Pd nanoclusters during the rapid cooling and interruption of the catalytic process. Considering the significantly 
smaller average size of Pd species derived from EXAFS (Table 1 ), the presence of such large Pd nanoparticles is partially due to the promoted aggregation of the Pd nanoclusters transformed from resting $\mathrm{Pd}$ complexes especially under the condition of solvent evaporation. The large particle size also implies that much smaller Pd clusters should also be present in the MOF crystals. Indeed, the small Pd clusters and mononuclear Pd complexes were captured by EDS mapping which showed clear Pd signals within the entire MOF particles (Figures $9 b_{2}-9 b_{4}$ ). The EDS spectra also confirmed that $\mathrm{Pd}$ species remained inside the MOF crystals at all stages of the reaction, although the $\mathrm{Pd} / \mathrm{Cr}$ ratio gradually decreased with time (Figures S12-S13, Section S11).

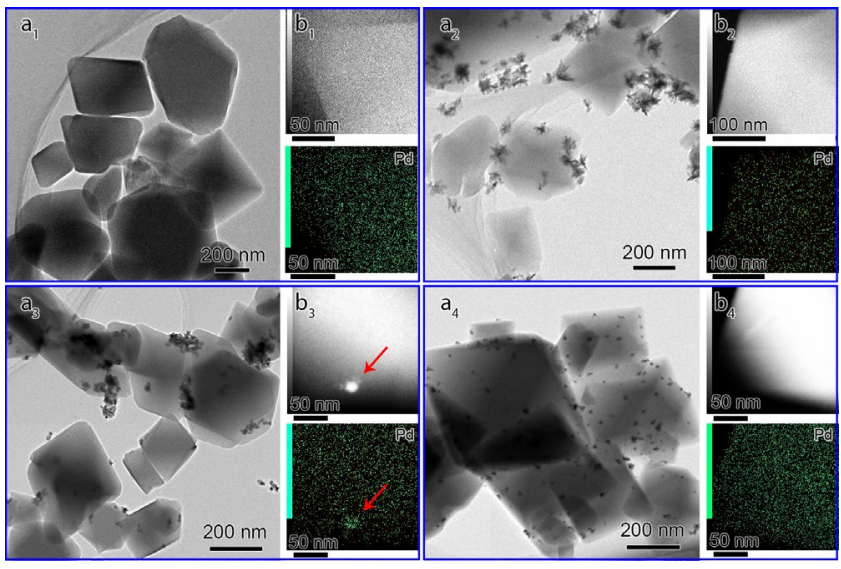

Figure 9. TEM images (a) and STEM image and EDS mapping (b) of Pd(II)@MIL-101- $\mathrm{NH}_{2}$ at various stages during the Heck reaction: at $0 \%$ (a1-b1), 25\% (a2-b2), 54\% (a3-b3) and > 99\% (a4-b4) conversion. While Pd nanoparticles are observed in all samples except the initial one, smaller Pd species (monomers, nanoclusters) are found to be homogenously distributed in the MIL-101- $\mathrm{NH}_{2}$ crystals throughout the reaction. The arrows in Figure $8 \mathrm{~b}_{3}$ indicate a Pd nanoparticle on the surface of the MOF.

The lack of recyclability of the MOF under the Heck coupling conditions indicates that not only the possible large Pd nanoparticles observed outside the MOF crystals by TEM, but also the small Pd species within the MOF crystals were already inert. This information is extremely important as it proves that it was neither the Pd leaching nor the Pd aggregation itself that led to the deactivation of the catalyst. Instead, the deactivation was caused by the poisoning of $\mathrm{Cl}^{-}$ions. Furthermore, the operando PXRD data proves that both MIL-101- $\mathrm{NH}_{2}$ and MIL-88B-NH were completely stable and no structural changes occurred under these reaction conditions (Figure S14, Section S12). Based on all information acquired, a clear picture emerges. The deactivation of the catalyst is not of a physical nature. Different from the structural degradation factors commonly suggested in the literature such as Pd leaching and agglomeration or MOF decomposition, the predominant deactivation pathway here is of a chemical nature. The irreversible capping of small Pd clusters with chloride ligands makes the reactive sites inaccessible to the reaction partners, long before Pd leaching or aggregation becomes a major issue.

\section{Recyclability}

With the above information in hand, we revisited the issue of recyclability. Initial studies showed a dramatic loss of activity in the second cycle, after the catalyst was recovered, washed and dried. However, when fresh reagents were added during the reaction phase of high activity, before a complete inhibition by $\mathrm{Cl}^{-}$ions was achieved, a high TOF could be maintained for at least 3 cycles. Despite the disturbance introduced by fresh reagents (temperature, solubility, reagents ratios) the reaction was faster than what would have been necessary to convert three batches of starting materials by fresh catalysts (Section S13). This experiment was purely illustrative and does not represent a practical experimental procedure. However, it suggests that operation under continuous flow would be a suitable way to improve the total turnover of the catalyst. $\mathrm{Cl}^{-}$ions could be washed away at the beginning of the experiment and a constant feed of fresh reagents would postpone the deactivation process.

Even though the recyclability of the material did not work as expected, we observed remarkable differences when comparing the activity of the $\mathrm{Pd}(\mathrm{II}) @ \mathrm{MOF}$ with its homogeneous counterparts. When the reaction was performed using the same palladium precursors (i.e. $\mathrm{Na}_{2} \mathrm{PdCl}_{4}$ and $\mathrm{PdCl}_{2}(\mathrm{MeCN})_{2}$ ) as catalysts without being impregnated into the MOF support, the yields dropped to $42-43 \%$ for both $\mathrm{Pd}$ (II) salts. This clearly shows the beneficial effect of the MOF support in this catalysis.

\section{Discussion}

The correlation of data from multiple characterization techniques portrays Pd@MIL-101- $\mathrm{NH}_{2}$ and Pd@MIL-88B-NH $\mathrm{N}_{2}$ as heterotopic multifaceted catalysts with more than one mode of action. In their as-synthesized dry form, both Pd(II)@MOF precatalysts contain Pd centers in a + II oxidation state and square planar coordination geometry, bearing two anionic $\mathrm{Cl}^{-}$ligands. When the catalyst was mixed with the other reagents except for olefin, the chloride ligands were immediately released and replaced by neutral nitrogen ligands, forming a cationic complex favored by the polar aqueous environment. Upon olefin addition in the presence of water, $\mathrm{Pd}(\mathrm{II})$ was rapidly reduced to $\mathrm{Pd}(0)$ even at room temperature. The freshly reduced $\mathrm{Pd}$ underwent a fast oxidative addition, initiating the catalytic cycle. The Heck coupling product was already detectable immediately after reaching $60^{\circ} \mathrm{C}$, proving that mononuclear $\mathrm{Pd}(\mathrm{II})$ complexes attaching to the linkers of the MOFs were competent active species to catalyze this transformation at relatively low temperatures.

The first catalytic turnovers have taken place inside the MOF pores, and proceeded with comparable rate for both Pd@MIL$101-\mathrm{NH}_{2}$ and $\mathrm{Pd} @ \mathrm{MIL}-88 \mathrm{~B}-\mathrm{NH}_{2}$ catalysts. During the first cycle, the coordination to the amino-terephthalate linker was lost in the case of MIL-101- $\mathrm{NH}_{2}$, leading to the formation of an even more electron-deficient Pd species, which could travel through the pores. A second oxidative addition could not be initiated by this form of electrophilic Pd, which instead gradually agglomerated into small nanoclusters. The resulting mixture of the mobile mononuclear $\mathrm{Pd}$ complexes and the $\mathrm{Pd}$ nanoclusters was inert at $60{ }^{\circ} \mathrm{C}$, and became active in the catalytic cycle at $90{ }^{\circ} \mathrm{C}$. However, upon depletion of the starting materials and further upon cooling the reaction mixture, the surface of $\mathrm{Pd}$ clusters was covered by $\mathrm{Cl}^{-}$ions and their catalytic properties were finally lost. Similar conclusions can be derived for Pd(II)@MIL-88B-NH 2 although the chelating coordination mode of the MOF and the more confined pore space attenuated the deactivation process. 
This study fits into a larger effort to bring a better understanding to the complex behavior of palladium under reaction conditions specific for $\mathrm{C}-\mathrm{C}$ and $\mathrm{C}$-heteroatom bond formation. ${ }^{36} \mathrm{In}$ recent years, it has become evident that the actual landscape of active species is more diverse and dynamic than previously believed. Starting from mononuclear Pd catalysts, formation of $\mathrm{Pd}$ clusters is often unavoidable. However, these particulate species not only represent an alternative resting state for Pd but can also get involved directly in the second stage of catalysis. The presence of rapidly inter-convertible species that possess different levels of reactivity makes it challenging to quantify precisely their contribution to the total observed catalytic effect. ${ }^{37}$ Moreover, commonly employed heterogeneity tests may not always provide reliable results. ${ }^{38}$ Without a better understanding of these phenomena, a rational design of superior catalysts would not be achievable.

Towards this goal, the method presented herein can reveal fine details of the reaction mechanism by monitoring more precisely the evolution of different Pd species and the effects of Pd phase transitions on its catalytic activity. Moreover, we are continuously working to expand the applicability of the method. Further development of the in situ reactor will make the acquisition of fluorescence XAS data in operando mode feasible. This would be especially beneficial to measure highly diluted samples or catalysts with relatively low absorption edge energies. Furthermore, the new generation of synchrotron radiation sources will provide great opportunities to improve the time resolution and investigate reactions with significantly shorter halflifetimes.

\section{Conclusions}

The mechanism of a Pd@MOF-catalyzed Heck C-C coupling reaction was investigated in detail using a newly developed reaction cell suitable for operando studies of heterogeneous catalysts. For the first time we probed the entire lifetime of the catalyst and revealed fine details of the reaction mechanism that would otherwise remain hidden. Different active species operating at different reaction stages and under different reaction conditions have been identified, together with their activation and deactivation pathways. The irreversible deactivation of the catalyst was provoked neither by leaching of the active species, nor by decomposition of the crystalline framework. Instead a chemical deactivation mechanism was identified, in which $\mathrm{Cl}^{-}$ ions cover the surface of transformed Pd clusters and nanoparticles, blocking the access of starting materials to the active sites. This information can be used to prolong the lifetime of the catalyst and to design improved catalysts and processes in the

(1) Egorova, K. S.; Ananikov V. P. Angew. Chem. Int. Ed. 2016, 55, 12150-12162.

(2) Jutand, A. Mechanisms of the Mizoroki-Heck Reaction (Chapter 1), in The Mizoroki-Heck Reaction (ed M. Oestreich), 2009, John Wiley \& Sons, Ltd, Chichester, UK.

(3) For some of the most recent reviews discussing catalysis with MOFs, see: a) Cohen, S. M.; Zhang, Z.; Boissonnault, J. A. Inorg. Chem. 2016, 55, 7281-7290; b) Dhakshinamoorthy, A.; Asiri, A. M.; Garcia, H. Catal. Sci. Technol. 2016, 6, 5238-5261; c) Dhakshinamoorthy, A.; Asiri, A. M.; Garcia, H. Chem. Soc. Rev. 2015, 44, 19221947; d) Chughtai, A. H.; Ahmad, N.; Younus, H. A.; Laypkov, A.; Verpoort, F. Chem. Soc. Rev. 2015, 44, 6804-6849; e) Evans, J. D.; future. Importantly, the method described is widely applicable to study diverse chemical reactions catalyzed by transition metals, including both homogeneous and heterogeneous systems, and has the potential to provide unprecedented insight into the fine details of the mechanism. Other complex mechanisms of MOF-catalyzed processes are currently under investigation in our laboratories.

\section{ASSOCIATED CONTENT}

Supporting Information Catalysts syntheses; optimization of reaction conditions, substrate scope and recycling experiments; additional studies of kinetic profiles by ${ }^{1} \mathrm{H}$ NMR; details on the XAS and PXRD data collection; XAS data treatment and refinement results; additional TEM and EDS results. This material is available free of charge via the Internet at http://pubs.acs.org.

\section{AUTHOR INFORMATION}

\section{Corresponding Authors}

*xzou@mmk.su.se

*belen.martin.matute@su.se

*ingmar.persson@slu.se

\section{Author Contributions}

$\$$ These authors contributed equally to this work.

Notes

The authors declare no competing financial interest.

\section{ACKNOWLEDGMENT}

This work has been supported by the MATsynCELL project through Röntgen-Ångström Cluster, supported by the Swedish Research Council (VR) and the German Federal Ministry of Education and Research (BMBF). We are also thankful to the Berzelii Center EXSELENT, the Swedish Research Council and the Project Management Organization at DESY (Deutsches Electronen-Synchrotron). The allocation of beamtime at BM01B (SNBL), European Synchrotron Radiation Facility (ESRF) is gratefully acknowledged. A.K.I. is supported by the Knut and Alice Wallenberg Foundation (KAW) through the MAX IV postdoctoral scholarship. B.M.-M. was supported by VINNOVA through a VINNMER grant. We thank KAW for the project grant 3DEM-NATUR and a grant for purchasing the TEMs. We thank Prof. Lynne McCukser for assistance during the beamtime applications, and the staff of beamline BM01B (SNBL), particularly Dr. Michela Brunelli and Dr. Hermann Emerich at the ESRF for the assistance during data collection. We also thank Dr A. Bermejo Gómez for helpful discussions.

\section{REFERENCES}

Sumby C. J.; Doonan, C. J. Chem. Soc. Rev. 2014, 43, 5933-5951; f) Gascon, J.; Corma, A.; Kapteijn, F.; Llabres i Xamena, F. X. ACS. Catal. 2014, 4, 361-378; g) Janssen, K. P. F.; De Cremer, G.; Neely, R. K.; Kubarev, A. V.; Van Loon, J.; Martens, J. A.; De Vos, D. E.; Roeffaers, M. B. J.; Hofkens, J. Chem. Soc. Rev. 2014, 43, 990-1006; h) Valvekens, P.; Vermoortele, F.; De Vos, D. Catal. Sci. Technol. 2013, 3, 1435-1445; i) Rogge, S. M. J.; Bavykina, A.; Hajek, J.; Garcia, H.; Olivos-Suarez, A. I.; Sepúlveda-Escribano, A.; Vimont, A.; Clet, G.; Bazin, P.; Kapteijn, F.; Daturi, M.; Ramos-Fernandez, E. V.; Llabrés i Xamena, F. X.; Van Speybroeck, V.; Gascon, J. Chem. Soc. Rev. 2017, 46, 3134-3184; j) Leus, K.; Liu, Y. Y; Voort P. V. D. Cat. Rev. Sci. Eng. 2014, 56, 1-56. 
(4) For recent reviews, discussing the complexity of heterogeneous catalytic mechanisms, see: a) Eremin, D. B.; Ananikov, V. P. Coord. Chem. Rev. 2017, 346, 2-19; b) Schauermann, S.; Freund, H.-J. Acc. Chem. Res. 2015, 48, 2775-2782; c) Schauermann, S.; Nilius N.; Shalkhutdinov, S.; Freund, H.-J. Acc. Chem. Res. 2013, 46, 1673-1681; d) Yang, X.-F.; Wang, A.; Qiao, B.; Li, J.; Liu, J.; Zhang, T. Acc. Chem. Res. 2013, 46, 1740-1748.

(5) Metzger, E. D.; Comito, R. J.; Hendon, C. H.; Dinca, M. J. Am. Chem. Soc. 2017, 139, 757-762.

(6) Morris, R. J.; Russell Jr., J. N.; Karwacki C. J. J. Phys. Chem. Lett. 2015, 6, 4923-4926.

(7) a) Bordiga, S.; Groppo, E.; Agostini, G.; van Bokhoven, J. A.; Lamberti, C. Chem. Rev. 2013, 113, 1736-1850; b) Singh, J.; Lamberti, C.; van Bokhoven, J. A. Chem. Soc. Rev. 2010, 39, 4754-4766; c) Bordiga, S.; Bonino, F.; Lillerud, K. P.; Lamberti, C. Chem. Soc. Rev 2010, 39, 4885-4927.

(8) a) Jung, U.; Elsen, A.; Li, Y.; Smith, J. G.; Small, M. W.; Stach E. A.; Frenkel, A. I.; Nuzzo, R. G. ACS Catal. 2015, 5, 1539-1551; b) Smit, E. De; Cinquini, F.; Beale, A. M.; Safonova, O. V; Beek, W. Van; Sautet, P.; Weckhuysen, B. M.; Supe, N.; Horowitz, R. J.; Cedex, F.G. J. Am. Chem. Soc. 2010, 132, 14928-14921; c) Rønning, M.; Tsakoumis, N. E.; Voronov, A.; Johnsen, R. E.; Norby, P.; Van Beek, W.; Borg, Ø; Rytter, E.; Holmen, A. Catal. Today 2010, 155, 289-295; d) van Beek, W.; Safonova, O. V.; Wiker, G.; Emerich, H. Phase Transitions 2011, 84, 726-732; e) Grunwaldt, J.-D.; Clausen, B. S. Topics Catal. 2002, 18, 37-43; f) Matam, S. K.; Aguirre, M. H.; Weidenkaff, A.; Ferri, D. J. Phys. Chem. C 2010, 114, 9439-9443; g) Reina, T. R.; Xu, W.; Ivanova, S.; Centeno, M. Á.; Hanson, J.; Rodriguez, J. A.; Odriozola, J. A. Catal. Today 2013, 205, 41-48; h) Cassinelli, W. H.; Martins, L.; Passos, A. R.; Pulcinelli, S. H.; Santilli, C. V.; Rochet, A.; Briois, V. Catal. Today 2014, 229, 114-122; i) Braglia, L.; Borfecchia, E.; Martini, A.; Bugaev, A. L.; Soldatov, A. V; Øien-Ødegaard, S.; Bleken, B. T. L.; Olsbye, U.; Lillerud, K. P.; Lomachenko, K. A.; Agostini, G.; Manzoli, M.; Lamberti, C. Phys. Chem. Chem. Phys. 2017, 19, 27489-27507; j) Andersen, C. W.; Borfecchia, E.; Bremholm, M.; Jørgensen, M. R. V.; Vennestrøm, P. N. R.; Lamberti, C.; Lundegaard, L. F.; Iversen, B. B. Angew. Chemie Int. Ed. 2017, 56, 10367-10372; k) Barzan, C.; Piovano, A.; Braglia, L.; Martino, G. A.; Lamberti, C.; Bordiga, S.; Groppo, E. J. Am. Chem. Soc. 2017, 139, 17064-17073; 1) Øien, S.; Agostini, G.; Svelle, S.; Borfecchia, E.; Lomachenko, K. A.; Mino, L.; Gallo, E.; Bordiga, S.; Olsbye, U.; Lillerud, K. P.; Lamberti, C. Chem. Mater. 2015, 27, 1042 1056; m) Zhou, Y.; Doronkin, D. E.; Chen, M.; Wei, S.; Grunwaldt, J.D. ACS Catal. 2016, 6, 7799-7809; n) Stötzel, J.; Frahm, R.; Kimmerle, B.; Nachtegaal, M.; Grunwaldt, J.-D. J. Phys. Chem. C 2012, 116, 599609; o) Doronkin, D. E.; Casapu, M.; Günter, T.; Müller, O.; Frahm, R.; Grunwaldt, J.-D. J. Phys. Chem. C 2014, 118, 10204-10212; p) Wezendonk, T. A.; Santos, V. P.; Nasalevich, M. A.; Warringa, Q. S. E.; Dugulan, A. I.; Chojecki, A.; Koeken, A. C. J.; Ruitenbeek, M.; Meima, G.; Islam, H. U.; Sankar, G.; Makkee, M.; Kapteijn, F.; Gascon, J. ACS Catal. 2016, 6, 3236-3247.

(9) a) Gorlin, Y.; Lassalle-Kaiser, B.; Benck, J. D.; Gul, S.; Webb, S. M.; Yachandra, V. K.; Yano, J.; Jaramillo, T. F. J. Am. Chem. Soc. 2013, 135, 8525-8534; b) Newton, M. A.; Brazier, J. B.; Barreiro, E. M.; Parry, S.; Emmerich, H.; Adrio, L. A.; Mulligan, C. J.; Hellgardt, K.; Hii, K. K. (Mimi). Green Chem. 2016, 18, 406-411.

(10) a) Grunwaldt, J.-D.; Caravati, M.; Baiker, A. J. Phys. Chem. B 2006, 110, 9916-9922; b) Lee, A. F.; Ellis, C. V.; Naughton, J. N.; Newton, M. A.; Parlett, C. M. A.; Wilson, K. J. Am. Chem. Soc. 2011, 133, 5724-5727; c) Parlett, C. M. A.; Gaskell, C. V.; Naughton, J. N.; Newton, M. A.; Wilson, K.; Lee, A. F. Catal. Today 2013, 205, 76-85.

(11) a) Reimann, S.; Stötzel, J.; Frahm, R.; Kleist, W.; Grunwaldt, J. D.; Baiker, A. J. Am. Chem. Soc. 2011, 133, 3921-3930; b) Brazier, J. B.; Nguyen, B. N.; Adrio, L. A.; Barreiro, E. M.; Leong, W. P.; Newton, M. A.; Figueroa, S. J. A.; Hellgardt, K.; Hii, K. K. M. Catal. Today 2014, 229, 95-103; c) Ellis, P. J.; Fairlamb, I. J. S.; Hackett, S. F. J.; Wilson, K.; Lee, A. F. Angew. Chem., Int. Ed. 2010, 49, 1820 1824; d) Fiddy, S. G.; Evans, J.; Neisius, T.; Newton, M. A.; Tsoureas, N.; Tulloch, A. A. D.; Danopoulos, A. A. Chem. Eur. J. 2007, 13, 3652-3659.
(12) Zalesskiy, S. S.; Ananikov, V. P. Organometallics 2012, 31, 2302-2309.

(13) For general aspects of MOF chemistry, see: a) Howarth, A. J.; Peters, A. W.; Vermeulen, N. A.; Wang, T. C.; Hupp, J. T.; Farha O. K. Chem. Mater. 2017, 29, 26-39; b) Howarth, A. J.; Liu, Y.; Li, P.; Li, Z.; Wang, T. C.; Hupp, J. T.; Farha O. K. Nat. Rev. Mater. 2016, 15018; c) Ferguson, A.; Liu, L.; Tapperwijn, S. J.; Perl, D.; Coudert, F.-X.; Van Cleuvenbergen, S.; Verbiest, T.; van der Veen, M. A.; Telfer, S. G. Nat. Chem. 2016, 8, 250-257; d) Furukawa, H.; Cordova, K. E.; O’ Keeffe, M.; Yaghi, O. M. Science 2013, 341, 1230444; e) Ferey, G.; Chem. Soc. Rev. 2008, 37, 191-214.

(14) For detailed discussions on the complexity and tunability of MOF supports, see: a) Fracaroli, A. M.; Siman, P.; Nagib, D. A.; Suzuki, M.; Furukawa, H.; Toste, F. D.; Yaghi, O. M. J. Am. Chem. Soc. 2016, 138, 8352-8355; b) Furukawa, H.; Muller, U.; Yaghi, O. M. Angew. Chem. Int. Ed. 2015, 54, 3417-3430; c) Sue, A. C.-H.; Manninge, R. V.; Deng, H.; Cao, D.; Wang, C.; Gandara, F.; Stoddart, J. F.; Whitelam, S.; Yaghi, O. M. Proc. Natl. Acad. Sci. 2015, 137, 7810-7816.

(15) For some interesting recent examples of MOFs in catalysis, see: a) Li, J.; Yu, X.; Xu, M.; Liu, W.; Sandraz, E.; Lan, H.; Wang, J.; Cohen, S. M. J. Am. Chem. Soc. 2017, 139, ASAP; b) Lv, X.-L.; Wang, K.; Wang, B.; Su, J.; Zou, X.; Xie, Y.; Li, J.-R.; Zhou, H.-C. J. Am. Chem. Soc. 2017, 139, 211-217; c) Yu, X.; Cohen, S. M. J. Am. Chem. Soc. 2016, 138, 12320-12323; d) Noh, H.; Cui, Y.; Peters, A. W.; Pahls, D. R.; Ortuno, M. A.; Vermeulen, N. A.; Cramer, C. J.; Gagliardi L.; Hupp, J. T.; Farha, O. K. J. Am. Chem. Soc. 2016, 138, 1472014 726; e) Rimoldi, M.; Nakamura, A.; Vermeulen, N. A.; Henkelis, J. J.; Blackburn, A. K.; Hupp, J. T.; Stoddart J. F.; Farha, O. K. Chem. Sci. 2016, 7, 4980-4984; f) Mon, M.; Ferrando-Soria, J.; Grancha, T.; Fortea-Perez, F. R.; Gascon, J.; Leyva-Perez, A.; Armentano, D.; Pardo, E. J. Am. Chem. Soc. 2016, 138, 7864-8767; g) Abednatanzi, S.; Derakhshandeh, P. G.; Abbasi, A.; Voort, P. V. D.; Leus, K. ChemCatChem 2016, 8, 3672-3679.

(16) a) Pascanu, V.; Yao, Q.; Bermejo Gómez, A.; Gustafsson, M.; Yun, Y., Wan, W.; Samain, L.; Zou, X.; Martín-Matute, B. Chem. Eur. J. 2013, 19, 17483-17493; b) Pascanu, V.; Hansen, P.; Bermejo Gómez, A.; Ayats, C.; Platero-Prats, A. E.; Johansson, M. J.; Pericàs, M. À.; Martín-Matute, B. ChemSusChem 2015, 8, 123-130.

(17) Pascanu, V.; Carson, F.; Vico Solano, M.; Su, J.; Zou, X.; Johansson, M. J.; Martin-Matute. B. Chem. Eur. J. 2016, 22, 3729-3737.

(18) Carson, F.; Pascanu, V.; Bermejo Gómez, A.; Zhang, Y.; Platero-Prats, A. E.; Zou, X.; Martín-Matute B. Chem. Eur. J. 2015, 21 , 10896-10902.

(19) Heidenreich, N.; Rütt, U.; Köppen, M.; Inge, A. K.; Beier, S.; Dippel, A.-C.; Suren, R.; Stock, N. Rev. Sci. Instrum. 2017, 88, 104102.

(20) Pascanu, V.; Bermejo Gómez, A.; Ayats, C.; Platero-Prats, A. E.; Carson, F.; Su, J.; Yao, Q.; Pericàs, M. A.; Zou, X.; Martín-Matute B. ACS Catal. 2015, 5, 472-479.(21) Abdala, P.M.; Mauroy, H.; van Beek, W. J. Appl. Cryst. 2014, 47, 449-457.

(22) George, G. N.; Pickering, I. J. EXAFSPAK - A Suite of Computer Programs for Analysis of X-ray Absorption Spectra, SSRL, Stanford, CA. 1993

(23) Thompson, A.; Attwood, D.; Gullikson, E.; Howells, M.; Kim, K.-J.; Kirz, J.; Kortright, J.; Lindau, I.; Liu, Y.; Pianetta, P.; Robinson, A.; Scofield, J.; Underwood, J.; Williams, G.; Winick, H. X-ray data booklet, Lawrence Berkeley National Laboratory, Berkeley, $3^{\text {rd }}$ Ed., 2009.

(24) Zabinsky, S. I.; Rehr, J. J.; Ankudinov, A.; Albers, R. C.; Eller, M. J. Phys. Rev. B 1995, 52, 2995-3009.

(25) Sigeev, A. S.; Peregudov, A. S.; Cheprakov, A. V.; Beletskaya I. P. Adv. Synth. Catal. 2015, 357, 417-429.

(26) a) Ahsen, B. V.; Bley, B.; Proemmel, S.; Wartchow, R.; Willner, H. Z. anorg. Allg. Chem. 1998, 624, 1225-1234; b) Gebauer, T.; Frenzen, G.; Dehnicke, K. Z. Naturforsch. 1992, 47, 1505-1512; c) Massa, W.; Wocadlo, S.; Dehnicke, K.; Gebauer, T. Z. Kristallogr. 1996, 211, 120-121.

(27) a) Kong, G.-Q.; Ou, S.; Zou, C.; Wu, C.-D. J. Am. Chem. Soc., 2012, 134, 19851-19857; b) Chen, L.; Rangan, S.; Li, J.; Jiang, H.; Li, Y. Green Chem. 2014, 16, 3978-3985. 
(28) a) IUPAC Stability Constants, Academic Sofware, Otley, UK; b) Hellquist, B.; Elding, L. I.; Ducommun, Y. Inorg. Chem. 1988, 27, 3620-3623; c) Vargaftik, M. N.; German, E. D.; Dogonadze, R. R.; Syrkin, Y. K. Dokl. Akad. Nauk SSSR 1972, 206, 370-376; d) Boily, J.F.; Seward, T. M. Geochim. Cosmochim. Acta 2005, 69, 3773-3789; e) Kragten J. Talanta 1980, 27, 375-377; f) Elding, L. I. Inorg. Chim. Acta 1972, 6, 647-651; g) Rittner, W.; Gulko, A.; Schmuckler, G. Talanta 1970, 17, 807-816.

(29) Henry, P. M.; Keith, J. A. Angew. Chem., Int. Ed., 2009, 48, 9038-9049.

(30) Jalilehvand, F. Structural of Hydrated Ions and Cyano Complexes by X-Ray Absorption Spectroscopy, Royal Institute of Technology, Stockholm, 2000, available at https://www.diva-portal.org/smash/get/diva2:8704/FULLTEXT01.pdf.

(31) Jentys, A. Phys. Chem. Chem. Phys. 1999, 1, 4059-4063.

(32) a) Pikna, L.; Milkovič, O.; Saksl, K.; Heželová, M.; Smrčová, M.; Puliš, P.; Michalik, S.; Gamcová, J. J. Solid State Chem. 2014,

212, 197-204; b) Agostini, G.; Lamberti, C.; Pellegrini, R.; Leofanti, G.; Giannici, F.; Longo, A.; Groppo, E. ACS Catal. 2014, 4, 187-194; c) Shimizu, K.; Kubo, T.; Satsuma, A.; Kamachi, T.; Yoshizawa, K. ACS Catal. 2012, 2, 2467-2474.

(33) Qi, W.; Huang, B.; Wang, M. Nanoscale Res. Lett. 2009, 4, 269 273.

(34) Krüger, S.; Vent, S.; Nörtemann, F.; Staufer, M.; Rösch, N. J. Chem. Phys. 2001, 115, 2082-2087.

(35) a) Phan, N. T. S.; Van Der Sluys, M.; Jones, C. W. Adv. Synth. Catal. 2006, 348, 609-679; b) Yu, L.; Huang, Y.; Wei, Z.; Ding, Y.; Su, C.; Xu, Q. J. Org. Chem. 2015, 80, 8677-8683; c) Martins, D. de L.; Alvarez, H. M.; Aguiar, L. C. S.; Antunes, O. A. C. Appl. Catal. A Gen. 2011, 408, 47-53; d) Thathagar, M. B.; ten Elshof, J. E.; Rothenberg, G. Angew. Chemie Int. Ed. 2006, 45, 2886-2890.

(36) a) Ananikov, V. P.; Beletskaya I. P. Organometallics 2012, 31, 1296-1604; b) Selivanova, A. V.; Tyurin, V. S.; Beletskaya, I. P. ChemPlusChem, 2014, 79, 1278-1283; b) Kashin A. N.; Ganina O. G.; Cheprakov A. V.; Beletskaya I. P. ChemCatChem 2015, 7, 2113-2121. (37) Pentsak, E. O.; Kashin, A. S.; Polynsky, M. V.; Kvashnina, K. O.; Glatzel, P.; Ananikov, V. P. Chem. Sci. 2015, 6, 3302-3313.

(38) Crabtree, R. H. Chem. Rev. 2012, 112, 1536-1554. 